\title{
Elements of a cognitive model of physics problem solving: Epistemic games
}

\author{
Jonathan Tuminaro and Edward F. Redish* \\ Department of Physics, University of Maryland, College Park, Maryland 20742-4111, USA
}

(Received 13 January 2007; published 6 July 2007)

\begin{abstract}
Although much is known about the differences between expert and novice problem solvers, knowledge of those differences typically does not provide enough detail to help instructors understand why some students seem to learn physics while solving problems and others do not. A critical issue is how students access the knowledge they have in the context of solving a particular problem. In this paper, we discuss our observations of students solving physics problems in authentic situations in an algebra-based physics class at the University of Maryland. We find that when these students are working together and interacting effectively, they often use a limited set of locally coherent resources for blocks of time of a few minutes or more. This coherence appears to provide the student with guidance as to what knowledge and procedures to access and what to ignore. Often, this leads to the students failing to apply relevant knowledge they later show they possess. In this paper, we outline a theoretical phenomenology for describing these local coherences and identify six organizational structures that we refer to as epistemic games. The hypothesis that students tend to function within the narrow confines of a fairly limited set of games provides a good description of our observations. We demonstrate how students use these games in two case studies and discuss the implications for instruction.
\end{abstract}

DOI: 10.1103/PhysRevSTPER.3.020101

PACS number(s): 01.40.Fk, 01.40.Ha

\section{INTRODUCTION}

Students learning physics at the college level often have considerable difficulty with problem solving despite the fact that problem solving is an integral part of most physics classes. ${ }^{1}$ Instructors may assume that these difficulties arise from a lack of mathematical skills, but little evidence has been presented to determine if this is the case. As part of a project to reform introductory algebra-based physics, ${ }^{2}$ we have collected extensive data of students learning physics and solving physics problems in a variety of environments. These data include some familiar but remarkable student behavior, such as (i) failing to use their personal knowledge in favor of misinterpretations of authority-based knowledge when reasoning in a formal context; (ii) using incorrect qualitative arguments to rebut a qualitative argument even when they know the correct formal argument. These behaviors are often quite robust, with students dramatically ignoring-appearing not even to hear-explicit suggestions from an instructor speaking to them directly. As a result, these behaviors look like what one might crudely describe as "misconceptions of expectations" about how to solve problems.

In order to make sense of these data, we propose a useful way of analyzing students' problem solving behavior in terms of locally coherent goal-oriented activities that we refer to as epistemic games. These games both guide and limit what knowledge students think is appropriate to apply at a given time. Identifying these games provides a way of parsing students' tacit expectations about how to approach solving physics problems.

We work in the context of a theoretical model that allows us to describe the cognitive processes that students usecorrectly and incorrectly-in the context of solving physics problems. We build on and extend ideas developed by diSessa, Sherin, and Minstrell ${ }^{3-7}$ and by Collins and Ferguson. ${ }^{8}$ Our theoretical approach fits into the more gen- eral theoretical framework we refer to as the resource model. ${ }^{9-12}$ In this broad model of student thinking, knowledge elements combine dynamically in associative structures activated by control structures in response to inputs from each other and from the environment.

Our theoretical framework offers researchers and educators a vocabulary (an ontological classification of cognitive structures) and grammar (a description of the relationship between the cognitive structures) to describe students' problem solving (and in particular, their understanding and use of mathematics) in the context of physics. ${ }^{13}$ Viewing student activity through the lens created by this framework can help researchers and educators understand how teacher-student interactions can more effectively help students develop their own problem-solving skills.

In the next section, we give a brief overview of our theoretical framework. In Sec. III, we describe a cognitive model for local coherence in problem solving in physics: epistemic games. In Sec. IV, we describe the setting of the study: the student population, the modified instructional environment, and the methodology used to collect and analyze our data. In Sec. V, we use our theoretical model to analyze two student problem-solving sessions. In the final section, we discuss some instructional implications, and present some conclusions. Much of the work described here is taken from the dissertation of Jonathan Tuminaro and more detail can be found there. ${ }^{14}$

\section{THEORETICAL FRAMEWORK}

Constructivism - the idea that a student constructs new knowledge based largely on what that student already knows - is the dominant paradigm in modern educational theories. ${ }^{15}$ The teacher's role in the constructivist paradigm is to create environments that help students undertake this construction accurately and effectively. In order to do this, it helps the teacher to know (i) the content and structure of the 
students' existing knowledge and (ii) how the students use this knowledge to construct new knowledge. There has been considerable direct observational research on the difficulties students have with various items of physics content; ${ }^{16,17}$ but to understand how students organize, access, and use their existing knowledge, we need a finer-grained understanding of how students think and respond. We need to know not just that students construct their new knowledge based on what they know, we need some understanding of how students construct new knowledge. To develop such an understanding, we need to know at least some of the basic elements of fundamental cognitive activities and how they are organized.

\section{A. Previous research}

Research on students' naïve knowledge and on expert and novice differences in problem solving are two topics that are particularly relevant to the current study. In this subsection, we give a brief review of these two areas of research.

\section{Students' naïve knowledge}

The fact that students bring prior naïve knowledge into a physics class has been well documented in the research literature. ${ }^{16,17}$ The level of abstraction at which the students' naïve knowledge is described, however, varies considerably. Some researchers describe student knowledge that does not align well with the scientific knowledge we are trying to teach as "misconceptions," "alternative conceptions," or "naïve theories." These researchers assume that students have internally consistent models of how aspects of the world work. ${ }^{18-21}$ Others describe the knowledge of beginning students in physics as fragmented and spontaneous. ${ }^{3,7}$ Both of these approaches contain elements of the truth. Sometimes student knowledge is fragmented, other times it appears coherent. In particular, expert knowledge is often highly coherent. In order to understand the novice-to-expert transition we must have a model that can bridge these two cognitive states. The resource model allows us to do this.

\section{Expert-novice differences in problem solving}

Researchers have studied problem solving in different contexts: problem solving associated with games such as chess, ${ }^{22}$ problem solving in mathematics, ${ }^{23-25}$ and mathematical problem solving in the context of physics. ${ }^{26-32}$ There is agreement that there are substantial differences between experts and novices; experts have more knowledge and organize it better (i.e., so that relevant knowledge is easily primed for activation). But most attempts to model the differences at a finer scale have focused on creating computer models that would solve problems effectively. Sometimes these models are algorithmic; ${ }^{33}$ sometimes they are based on heuristics extracted from expert informants. ${ }^{34}$ While these approaches can produce computer software that can carry out some tasks that human experts do, it is not at all clear that they correctly model how a human being learns and functions. (A good summary of the successes and limitations of this approach is given in d'Andrade. ${ }^{35}$ ) Other approaches are phenomenological, using expert heuristics to design learning environments that improve students' problem-solving skills. ${ }^{36,37}$

None of these approaches, however, help us understand how students make the transition from novice to expert. In order to make progress on these issues we have to understand how novices and experts approach problems, and we have to have effective ways of talking about and describing the differences. In this paper, we identify one concept, the epistemic game, that we hope will provide some first steps toward obtaining a more detailed analysis of the noviceexpert transition.

\section{B. Resource model}

If our goal is to teach a human being effectively, it is appropriate to build a theoretical model based on our knowledge of the functioning of that system (a human being) and not some other (a computer). ${ }^{38}$ In order to describe student behaviors, we want to create a model that is sufficiently coarse-grained that it allows us to describe observed behaviors and sufficiently fine-grained that it gives us insight into the mechanisms responsible for those behaviors. The resource model ${ }^{9-12}$ provides such a structure. It is based on a combination of three kinds of scholarship about the functioning human: neuroscience, cognitive science, and behavioral science. It permits us to begin to create a finer-grained understanding of student behavior that can bridge the alternative- and fragmented-conception models and can help us develop a more detailed understanding of the novice-toexpert transition.

Researchers in neuroscience, cognitive science, and behavioral science attempt to model human thought at a variety of grain sizes. Much has been learned in all these areas (though one has to be cautious in applying research results at a fine-grained level from neuroscience or cognitive science to real-world situations), but there is still much to be learned, and there is much that is still uncertain about what we know about human thinking. Nevertheless, we can model reasonably safely when the basic structural elements of neuroscience, the well-documented mechanisms of cognitive science, and the observations of real-world (ecological) ${ }^{39}$ behavior of real human beings acting in authentic situations all agree and support each other.

Note that in building the resource model we are not attempting to create a fundamental theory of human behavior. Rather, we are developing a theoretical framework or superstructure $^{10}$ within which plausible phenomenological models can be created that can help us understand what we see in our classrooms and that are also consistent with what is known about the fundamental mechanisms and operation of the brain.

\section{Basis of cognition}

A consistent model of cognition that is beginning to emerge from neuroscience and cognitive science is synthesized and documented in many books. ${ }^{40-43}$ In this model, cognitive elements of knowledge and memory are represented by networks of connected neurons. When someone 
recalls or uses the knowledge represented by a particular network, the neurons of the network are activated (increase their firing rate).$^{44}$ Particular knowledge elements tend to be multimodal (i.e., to involve activation and interpretation of multiple sensory and interpretive structures) and involve neurons in many parts of the brain. ${ }^{45}$ Cognitive networks arise from the building of associations among neurons through synapse growth. ${ }^{46}$ The association of neurons can vary in strength and increases with repeated associational activations. ${ }^{47,48}$

Neural connections can be excitatory or inhibitory ${ }^{46}$ This creates the possibility of executive processes that result in the selective activation of some networks and the suppression of others. ${ }^{49}$ Modern fMRI studies and neurophysiological studies with patients who have brain lesions suggest that the pre-frontal cortex is a primary site of a large number of control structures (though they are expected to occur in other parts of the brain as well). ${ }^{50-52}$

The critical elements of this model are the basic elements of knowledge stored in long-term memory, the way those elements are linked, and the way those linked structures are activated in different circumstances. We use the term knowledge element to describe any knowledge stored in long-term memory that activates as a single unit or chunk. We include both declarative and procedural knowledge. We refer to the linking patterns of association as knowledge structures and to the executive function that determines when those structures are activated as control structures. We broadly refer to all the elements of this model as resources.

This model only provides a framework. In order to develop a practical phenomenology, we need to identify various robust patterns of association of knowledge elements, i.e., specific knowledge structures, and demonstrate the value of recognizing these structures.

\section{Basic knowledge elements: Compilation}

A network corresponding to an element of knowledge becomes robust through practice and experience. For example, one can quickly and easily identify the combination of sensations associated with holding a cup of hot coffee. We effortlessly combine the perception of the pixels (activation of rods and cones) on our retina with the touch, smell, and taste of the coffee into a perception of what appears to be a single object. Neuroscientists call this binding, but we prefer to describe it as compilation..$^{53}$ Compilation of knowledge elements in associated knowledge structures results in new knowledge elements. They are seen as irreducible by the individual and can be used as a single chunk in working memory. ${ }^{54}$ The instructional implications of compilation are discussed elsewhere..$^{55}$

Note that a knowledge element may have a structure and that for some purposes it might be useful to decompose it into finer-grained knowledge elements even when the user sees it as irreducible. ${ }^{56}$ This is like considering molecules consisting of atoms. For some tightly bound molecules in some situations (e.g., molecules in a gas in kinetic theory) it suffices to consider the molecule as a single functioning unit without substructure. In other circumstances (e.g., situations in which chemical reactions occur or for more weakly bound molecules), it is essential to keep the molecule's structure in terms of atoms in mind.

\section{Patterns of association: Knowledge structures}

Because cognitive networks are extended and because neurons have large numbers of synapses with other neurons, an individual neuron may be a part of multiple mutually linked knowledge structures. As a result, activation of one network may result in the associated activation of other networks. Patterns of association develop, linking different resources in different situations. Learning occurs as the result of the growth of new synapses that result in changing the topology of existing networks. ${ }^{57}$ The patterns of association individuals develop may help or hinder them in solving physics problems. ${ }^{12}$

In this paper, we propose that a useful way to analyze some of the common associational structures in student approaches to physics problem solving is to describe them in terms of locally coherent, goal-oriented activities. We choose to call these epistemic games because of their similarity to the structures proposed by Collins and Ferguson. ${ }^{8}$ Note that the activities that Collins and Ferguson describe are normative-activities carried out by experts to solve problems. We extend their idea to one that is ethnographicdescriptive of observed student behavior. (Note that some other researchers have also extended their use of the term in this way. ${ }^{58,59}$ )

\section{Some specific resources: Reasoning primitives and intuitive mathematics}

A variety of specific relevant resources are available to most students studying physics. These include both knowledge about the physical world and knowledge about mathematics, both intuitive and formal.

Students use a form of intuitive knowledge about physical phenomena and processes that they have learned in their everyday life experiences to make sense of the physical world. ${ }^{60}$ DiSessa $^{3}$ proposes that students develop an intuitive sense of physical mechanism from everyday experience. This intuitive sense of physical mechanism arises from the activation and interaction of multiple cognitive resources that diSessa refers to as phenomenological primitives (p-prims).

The name, phenomenological primitives, is used to convey several key aspects of these cognitive structures. The word "phenomenological" reflects the idea that these resources are abstracted from everyday phenomena. For example, closer is stronger could be abstracted from the phenomenon that the closer one is to a fire, the warmer it feels. The word "primitive" reflects the idea that these resources are "irreducible and undetectable" to the user-they are often used as if they were self-explanatory. For example, asked why it is warmer closer to a fire, a student using closer is stronger may respond, "it just is." 61

Because of his focus on the irreducibility of p-prims with respect to the user, diSessa identifies p-prims at differing levels of abstraction: for example, force as mover and $a b$ stract balancing. Force as mover involves the very specific 
concept of an object moving under the influence of a force; whereas abstract balancing involves the general notion that two unspecified influences can be in a state of equilibrium. Because of the specific nature of p-prims like force as mover, diSessa proposes that there are thousands of p-prims corresponding to the myriad of physical experiences one may have in this complex world.

To reduce the extremely large number of p-prims and to group cognitive structures at their different levels of abstraction, we follow Redish ${ }^{10}$ and abstract from p-prims the notion of intuitive pieces of knowledge called reasoning primitives. Reasoning primitives are abstractions of everyday experiences that involve generalizations of classes of objects and influences. In this view a p-prim like force as mover results from mapping an abstract reasoning primitive like agent causes effect into a specific situation that involves forces and motion. The specific agent, in this case, is a force and the effect it causes is movement. When a reasoning primitive is mapped into a specific situation, we refer to it as a facet of that reasoning primitive. ${ }^{7}$ Agent causes effect could also be mapped into force as spinner, another p-prim identified by diSessa. ${ }^{3}$ This shows how the notion of reasoning primitives reduces the total number of resources necessary to describe students' previous knowledge about physical phenomena (compared to p-prims). In addition, agent causes effect and abstract balancing both reflect relationships between abstract influences and therefore exist at the same level of abstraction.

Another reason to consider the reasoning primitives underlying facets is to understand process components that may be addressable by instruction. If a student is using an appropriate reasoning primitive but has mapped it inappropriately, it may be simple to help the student change the mapping. This more fine-grained theoretical model activates different instructional responses than if one considers a particular p-prim to be an irreducible and robust "alternate conception."

Students can also activate a variety of resources from their intuitive mathematics knowledge, including intuitive sense of number, ${ }^{62}$ counting, ordering, a variety of grounding metaphors, ${ }^{63}$ symbolic forms, and interpretive devices. ${ }^{6}$ Since these mathematical resources do not play a critical role in the examples used here, however, we save their discussion for another publication (see Ref. 14).

\section{EPISTEMIC GAMES}

Students have a wealth of previous knowledge and ideas that they bring to bear when solving physics problems. To understand and talk about what students are doing, we need a description of the way their resources are organized.

To determine some of these organizational structures, we analyzed $11 \mathrm{~h}$ of video data drawn from about $60 \mathrm{~h}$ of videotapes of groups of students solving homework problems in a reformed algebra-based physics class. The context of the reforms and the methodology of the data collection and analysis are described in Sec. IV. In this section, we describe six locally coherent organizational control structures that we saw students using in these tapes. Examples of these games drawn from two case studies taken from the video data are given in Sec. V.

One of the most interesting characteristics of the student behaviors we observed was their local coherence. Over a period of a few minutes to half an hour, we saw students reasoning using a limited set of associated resources.

We can best describe these behaviors by adapting the idea of epistemic game (or, e-game, for short) introduced by Collins and Ferguson. ${ }^{8}$ Collins and Ferguson define an epistemic game as a complex "set of rules and strategies that guide inquiry." They introduce the idea of epistemic games to describe expert scientific inquiry across disciplines. Students in introductory physics courses are far from experts, so using scientists' approaches to inquiry as a norm by which to describe students' inquiry would not be appropriate. For this reason, we generalize the idea of epistemic games to be descriptive rather than normative. We define an epistemic game as:

"a coherent activity that uses particular kinds of knowledge and processes associated with that knowledge to create knowledge or solve a problem."10

The activities are "epistemic" in the sense that students engage in these activities as a means of constructing new knowledge. We use the word "game" in a very real sense; a particular game (like checkers or chess) is a coherent activity that has ontology components that identify the "things" of the game (players, pieces, and a playing board) and a structure (a beginning and an end, moves, rules) that makes it distinguishable from other activities. Similarly, an e-game has ontological components (concepts, principles, equations) and a structure (starting and ending states, allowed moves, rules). The simplest epistemic game identified by Collins and Ferguson is a familiar one: list making. Every list is implicitly an answer to a question-it builds knowledge to satisfy some goal. Some examples are: "What do I need from the grocery store?"; "What are the fundamental forces of nature?"; and, "What are the constituents of all matter?"

Note that the idea of a game here-a locally coherent set of behavioral rules for achieving a particular goal-is very general. Some of the behavioral science literature (especially in the opposite extremes of popularizations ${ }^{64}$ and mathematical economics ${ }^{65}$ ) has used the term game in this way. We focus here on epistemic games-games engaged in for the purpose of creating knowledge. Note that we are not claiming that students choose to play these games consciously or can articulate what game they are playing. We are describing their behavior, not their knowledge of their own behavior.

\section{A. Ontology of epistemic games}

Epistemic games have two ontological components: a knowledge base and an epistemic form. An e-game is not simply a structure of a set of associated knowledge; it is an activation of a pattern of activities that can be associated with a collection of resources. The collection of resources that an individual draws on while playing a particular e-game constitutes the knowledge base. For example, to answer a question like, "What are the fundamental forces of nature?" 
TABLE I. The ontological and structural components of epistemic games.

\begin{tabular}{clcl}
\hline \hline Ontological components & Structural components \\
\hline $\begin{array}{c}\text { Knowledge } \\
\text { base }\end{array}$ & $\begin{array}{l}\text { cognitive resources } \\
\text { associated with the } \\
\text { game }\end{array}$ & $\begin{array}{c}\text { Entry and } \\
\text { ending } \\
\text { conditions }\end{array}$ & $\begin{array}{l}\text { conditions for when to } \\
\text { begin and end playing a } \\
\text { particular game }\end{array}$ \\
$\begin{array}{l}\text { Epistemic } \\
\text { form }\end{array}$ & $\begin{array}{l}\text { Moves } \\
\text { guides inquiry }\end{array}$ & $\begin{array}{l}\text { activities that occur } \\
\text { during the course of an } \\
\text { e-game }\end{array}$ \\
\hline \hline
\end{tabular}

one needs to have some requisite knowledge to list the forces.

The epistemic form is a target structure, often an external representation that helps guide the inquiry during an epistemic game. For example, the epistemic form in the list making game is the list itself. The list is an external representation that cues particular resources and guides the progression of the inquiry. In some of the games we describe below, the epistemic form could be a written out series of steps, or the derivation of an equation or result.

\section{B. Structure of epistemic games}

The structural components of epistemic games include the entry and ending conditions of the game and the moves. The entry and ending conditions specify the beginning and the ending of the game. As we mentioned above, one may enter into the list making game as a means to answer a question. When solving physics problems, students' expectations about physics problems determine the entry and ending conditions. These expectations can depend on real-time categorizations of physics problems and/or on preconceived notions about the nature of problem solving in physics. Research by Hinsley and Hayes ${ }^{66}$ indicates that students can quickly categorize large classes of physics problems very shortly after reading the statement of the problem. In fact, these categorizations can be made after reading the first sentence. The students' ability to very quickly categorize physics problems may stem from their experience with and expectations about physics problem solving. These expectations and categorizations of physics problems affect which epistemic game the students (perhaps tacitly) choose to play. In addition, students' preconceived epistemological stances about problem solving in physics can affect their expectations. If students believe that problem solving in physics involves rote memorization of physics equations, that can affect the strategy they employ (i.e., which e-game they choose to play) and what they believe an answer in physics is (i.e., how they know they are done playing a particular game). ${ }^{67}$

The moves in an e-game are the steps and procedures that occur in the game. In the list-making game the moves may be to add a new item, combine two (or more) items, substitute an item, split an item, and remove an item. As we will see, a critical element of an epistemic game is that playing the game specifies a certain set of moves. What is particularly important about this is not just the moves that are included in the game, but also the moves that are excluded.
Table I summarizes the ontological and structural components of epistemic games.

\section{Epistemic games students play in introductory, algebra- based physics}

In this section we discuss some of the epistemic games that account for the different problem-solving strategies seen in our data. We identify six epistemic games that include most of the different problem-solving behaviors we have seen (see Table II). We do not claim that this list spans all possible problem-solving approaches that could be employed during problem solving in physics and we do not claim to have identified all possible moves within each game. ${ }^{68}$ If we had examined a different population of students or a different domain, it is possible that the list of epistemic games would be different, though we expect some of the games identified here to have broad applicability. We present these as examples of the type of structure we are proposing. In the next section, we present two case studies showing how analyzing student behavior in terms of these games helps make sense of what they do and do not do in the context of solving a specific problem.

Each of these games is described in more detail below. For each epistemic game we give a brief introduction and discuss its ontology and structure. Note that some of the games have common moves and one game may look like a subset of another. We identify them as distinct games because they have different ending conditions; students playing different games decide they are "done" when different conditions are met. Section V gives an example of students playing each of these games.

\section{Mapping Meaning to Mathematics}

The most intellectually complex epistemic game that we identify is Mapping Meaning to Mathematics. In this game,

TABLE II. List of epistemic games identified in our data set.

List of epistemic games

Mapping Meaning to Mathematics

Mapping Mathematics to Meaning

Physical Mechanism Game

Pictorial Analysis

Recursive Plug-and-Chug

Transliteration to Mathematics 


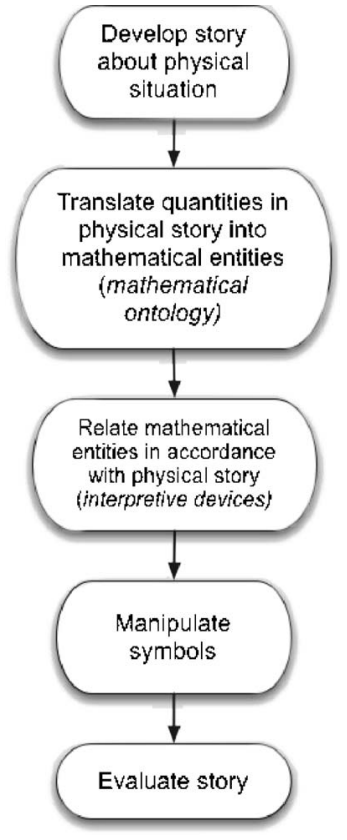

FIG. 1. Schematic diagram of some moves in the epistemic game Mapping Meaning to Mathematics.

students begin from a conceptual understanding of the physical situation described in the problem statement, and then progress to a quantitative solution. We identify five basic moves (see Fig. 1): (1) develop a story about the physical situation, (2) translate quantities in the physical story to mathematical entities, (3) relate the mathematical entities in accordance with the physical story, (4) manipulate symbols, and (5) evaluate and interpret the story.

The knowledge base for this game (as with all the games we identify) comes from the set of physics and mathematics resources. In general, however, different resources can be activated during the different moves of the game. During the development of the conceptual story (move 1), reasoning primitives are most often activated. That is, students often rely on their own conceptual understanding to generate this story-not on fundamental physics principles. Translating the conceptual story into mathematical entities (move 2) is difficult for most of the students in our population. Intuitive mathematics knowledge, symbolic forms, and interpretive devices may be activated during this move. Relating the mathematical entities to the physical story (move 3), again is difficult for students in our population, and depends on intuitive mathematics knowledge, symbolic forms, and interpretive devices. Once the physics equations are written, the symbolic manipulations (move 4) often are carried out without a hitch. This is probably because most of our students have had ample practice manipulating symbols. The evaluation of the story (move 5) can occur in many different ways. For example, students may check the solution with a worked example (or solution in the back of the book), students may check their quantitative answer with their conceptual story, or students may check their solution against an iconic example. Note that these evaluations do not necessarily correspond to an expert evaluation or what a teacher would want to see. A superficial similarity to previously seen results may

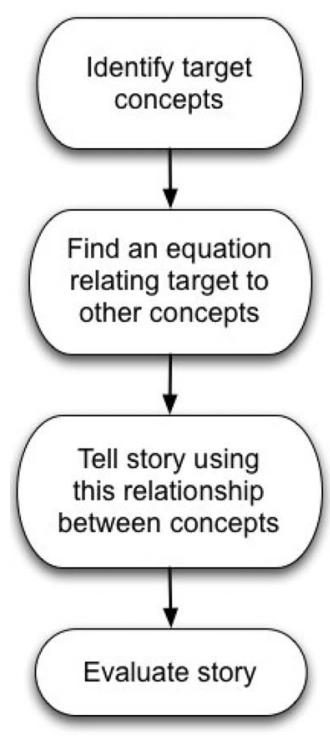

FIG. 2. Schematic diagram of some moves in the epistemic game Mapping Mathematics to Meaning.

suffice for the student to decide that the end condition of the game has been met.

The epistemic form for Mapping Meaning to Mathematics is typically the collection of mathematical expressions that the students generate during moves 2 and 3 . These expressions lead the direction of the inquiry. Note, however, that the epistemic form is not the entire story in this game. The interpretation (story) that goes with the series of mathematical expressions generated may or may not be explicitly expressed, depending on the instructions for giving a written output and the students' sense of how much "explanation" they are required to provide.

\section{Mapping Mathematics to Meaning}

The second most intellectually complex epistemic game that we identify is Mapping Mathematics to Meaning. In this game, students develop a conceptual story corresponding to a particular physics equation. The ontological components of Mapping Mathematics to Meaning are the same as those in Mapping Meaning to Mathematics. In particular, both games involve the same kind of knowledge base (mathematical resources) and the same epistemic form (physics equations). However, the particular resources and physics equations that are used in each game can vary from problem to problem.

In addition, the structural components of the two games are different. In Mapping Meaning to Mathematics, students begin with a conceptual story and then translate it into mathematical expressions. In contrast, in Mapping Mathematics to Meaning students begin with a physics equation and then develop a conceptual story. ${ }^{69}$ The structural differences between these two games make them distinguishable from each other.

We identify four moves in Mapping Mathematics to Meaning (see Fig. 2): (1) identify target concepts, (2) find an equation relating the target concepts to other concepts, (3) tell a story using this relationship between concepts, and (4) evaluate story. 


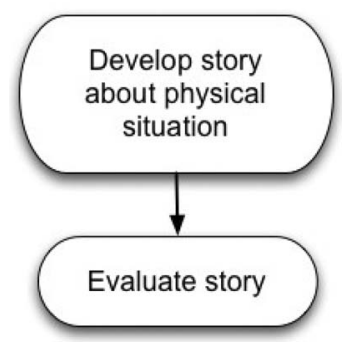

FIG. 3. Schematic diagram of some moves in the epistemic game Physical Mechanism.

\section{Physical Mechanism Game}

In the Physical Mechanism Game students attempt to construct a physically coherent and descriptive story based on their intuitive sense of physical mechanism. The knowledge base for this game consists of reasoning primitives. In this game students do not make explicit reference to physics principles or equations.

The ontology of the Physical Mechanism Game is different than in Mapping Meaning to Mathematics and Mapping Mathematics to Meaning. The epistemic forms in the latter two games explicitly involve physics equations. In contrast, the epistemic form in the Physical Mechanism Game does not. The form in this case is a story-a description of the mechanism of what is happening in terms of physical principles. Although the epistemic form is different, the same set of resources (intuitive mathematics knowledge, reasoning primitives, symbolic forms, and interpretive devices) may be active in this game as in the previous games.

The structure of the Physical Mechanism Game is similar to the first move in Mapping Meaning to Mathematics-both involve the development of a conceptual story. However, we can distinguish the two because the Physical Mechanism Game represents a separate, coherent unit of student activities; it has a different end state. In Mapping Meaning to Mathematics, after move 1 students tend to go on to move 2, then move 3, etc. After (1) creating and (2) evaluating the conceptual story developed in the Physical Mechanism Game (see Fig. 3) students decide they are done. The activities that follow this game do not cohere with the conceptual story-in direct contrast with the activities that follow move 1 in Mapping Meaning to Mathematics.

\section{Pictorial Analysis Game}

In the Pictorial Analysis Game, students generate an external spatial representation that specifies the relationship between influences in a problem statement. For example, students who make a schematic drawing of a physical situation, a free-body diagram, or a circuit diagram are all playing the Pictorial Analysis Game.

In this game, as with all the games previously discussed, the knowledge base consists of all the resources listed above plus some representational translation resources. The epistemic form in this game is the distinguishing characteristic. The epistemic form is a schematic or diagram that the students generate. For example, if the students draw a circuit

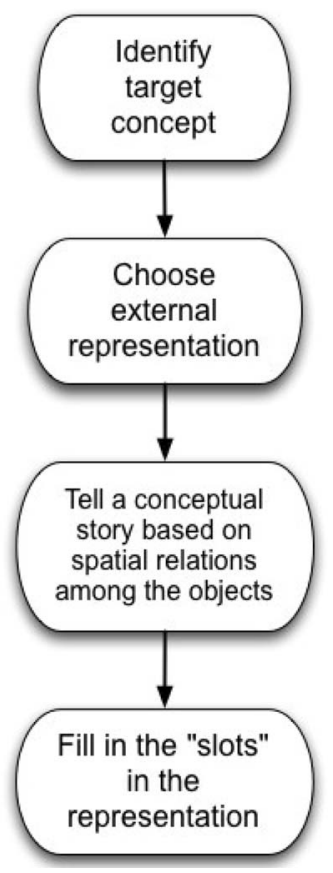

FIG. 4. Schematic diagram of some moves in the epistemic game Pictorial Analysis.

diagram during their inquiry, then that diagram serves as an epistemic form that guides their inquiry. In the same way, a schematic drawing and/or free-body diagram could each serve as a target structure that guides inquiry.

The moves in this game are largely determined by the particular external representation that the students choose. For example, if the students choose to draw a free-body diagram, then one move is to determine the forces that act upon the object in question whereas if the students choose to draw a circuit diagram, then one move is to identify the elements (e.g., resistors, capacitors, batteries, etc.). Despite differences that may arise based on the particular external representation chosen, there are three moves that are common to all instantiations of the Pictorial Analysis Game (see Fig. 4): (1) determine the target concept, (2) choose an external representation, (3) tell a conceptual story about the physical situation based on the spatial relation between the objects, and (4) fill in the slots in this representation. An example of students who choose to draw a free-body diagram while playing the Pictorial Analysis Game is given in our first case study in Sec. $V^{70}$

\section{Recursive Plug-and-Chug}

In the Recursive Plug-and-Chug Game students plug quantities into physics equations and churn out numeric answers, without conceptually understanding the physical implications of their calculations.

Students do not generally draw on their intuitive knowledge base while playing this game. Instead, they simply identify quantities and plug them into an equation. Consequently, students playing this game rely only on their syntactic understanding of physics symbols, without attempting to understand these symbols conceptually. That is, other cogni- 


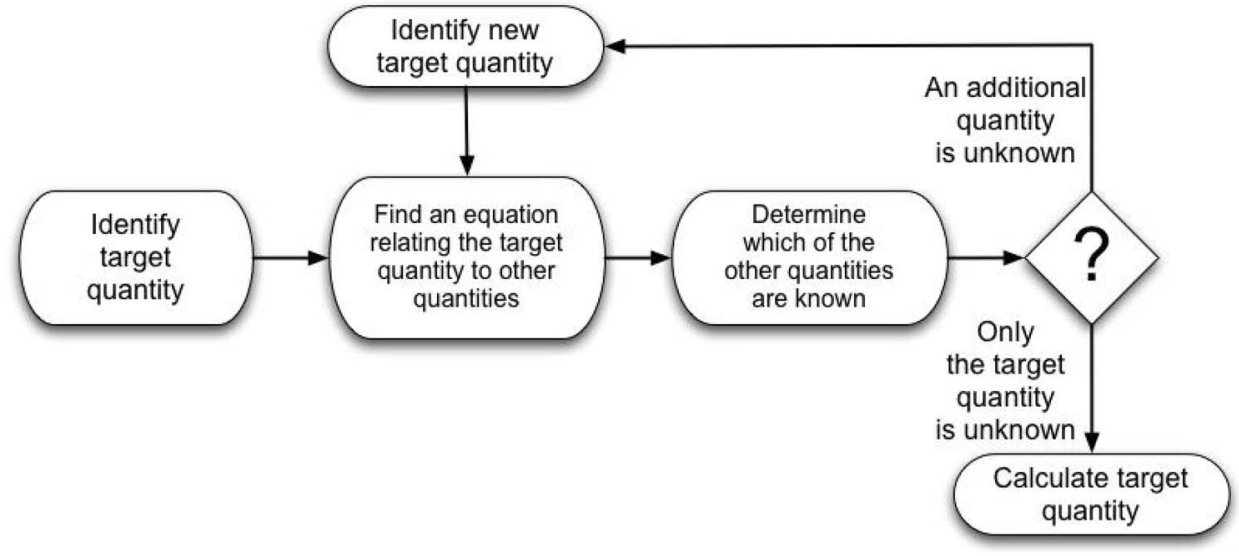

FIG. 5. Schematic diagram of some moves in the epistemic game Recursive Plug-and-Chug. tive resources (such as intuitive mathematics knowledge, reasoning primitives, symbolic forms, and interpretive devices) are usually not active during this game.

The epistemic form in Recursive Plug-and-Chug is similar or even identical to that in Mapping Meaning to Mathematics and Mapping Mathematics to Meaning. Each game has physics equations as part of the epistemic form, but the resources that are active (i.e., knowledge base) are different. The rules and strategies that are employed in Recursive Plugand-Chug differ from those in Mapping Meaning to Mathematics and Mapping Mathematics to Meaning-even though the epistemic form may be the same. A distinguishing feature of Recursive Plug-and-Chug is the resources that are not activated during this game.

In Recursive Plug-and-Chug, the students first identify a target quantity. This is similar to the first move in Mapping Mathematics to Meaning, but it differs in that here the students only identify the quantity and its corresponding symbol-they do not attempt to understand conceptually what the quantity represents physically as in Mapping Mathematics to Meaning. Second, the students identify an equation that relates the target quantity to other quantities, but they do not attempt to create a story that justifies the use of that equation. Third, the students identify which quantities are known and which quantities are unknown. If the target quantity is the only unknown, then they can proceed to calculate the answer. However, if there are additional unknowns, then they must choose a subgoal and start this process over. Herein lies the "recursive" nature inherent in this game. Figure 5 shows a schematic depiction of the moves in this game.

\section{Transliteration to Mathematics}

Research on problem solving indicates that students often use worked examples to develop solutions to novel problems. ${ }^{71,72}$ Transliteration to Mathematics is an epistemic game in which students use worked examples to generate a solution without developing a conceptual understanding of the worked example. "Transliterate" means "to represent (letters or words) in the corresponding characters of another alphabet." ${ }^{73}$ In the Transliteration to Mathematics game students map the quantities from a target problem directly into the solution pattern of an example problem.
Because students use the symbolism in this game without conceptual meaning, usually only resources associated with the syntactic structure of equations are active during this game. The solution pattern of the target example serves as the epistemic form for the Transliteration to Mathematics game.

The moves in this game are as follows: (1) identify a target quantity, (2) find a solution pattern that relates to the current problem situation, (3) map quantities in the current problem situation into that solution pattern, and (4) evaluate the mapping (see Fig. 6). Many students find moves 2 and 3 very tricky. Many times students may find a solution pattern that they think relates to the current problem, when in fact it does not.

\section{SETTING OF THE STUDY AND METHODOLOGY}

This study was done as a part of a project carried out at the University of Maryland ${ }^{2}$ to determine whether an intro-

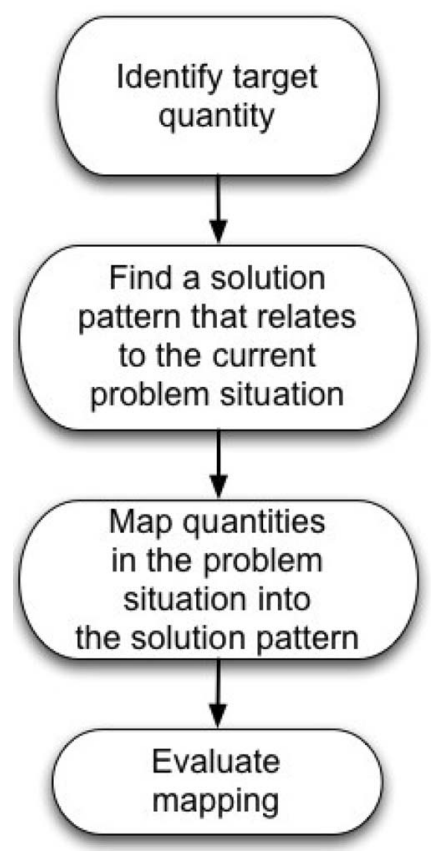

FIG. 6. Schematic diagram of some moves in the epistemic game Transliteration to Mathematics. 
ductory physics course could serve as a venue to help biology students learn to see science as a coherent process and way of thinking, rather than as a collection of independent facts; and whether this could be achieved within the context of a traditional large-lecture class without a substantial increase in instructional resources. The project adopted reforms that were well-documented to produce conceptual gains and adapted them to create a coherent package that produced epistemological and metacognitive gains. We were able to accomplish this without sacrificing the conceptual gains associated with these reforms. ${ }^{74}$

Data on the student responses to the modified environment were collected in a variety of ways in order to provide triangulation on the learning process of individual students and evaluations of the overall class results. The learning environments were constructed to encourage students to learn in group discussions taking place both in and out of the classroom. Hundreds of hours of these group discussions were recorded on video and provide the data for this project. In addition, all student homework, quizzes, and exams were scanned before grading. Finally, we gave pre-post conceptual $\left(\mathrm{FCI}^{75}\right.$ and $\mathrm{FMCE}^{76}$ ) and epistemological attitude surveys (modified MPEX ${ }^{77}$ ).

\section{A. Student population}

The students in this study were enrolled in an introductory, algebra-based physics course. They were approximately $60 \%$ female; more than $70 \%$ were juniors and seniors, about $50 \%$ were biological science majors, and about $40 \%$ were pre-meds. (There were some year-to-year fluctuations in these numbers.) A particularly interesting statistic for this study is that more than $95 \%$ of the students had successfully completed two semesters of calculus, yet they chose to enroll in an algebra-based introductory physics course despite the availability of a calculus-based alternative. Data were collected in ten semester-long classes over a 4-yr period from a total of more than 1000 students.

\section{B. Structure of the modified course}

The course had four major structural components. The homework, the lecture, the discussion, and the laboratory were all modified to be nontraditional in some fashion. In addition, we attempted to make all parts of the course coherent with each other. We believe that the overall epistemological orientation of the class was responsible, at least in part, for the students' willingness to spend long periods working together on individual problems and for some of the behaviors we observed, such as discussing the physics qualitatively before starting to write equations. We describe here the details of the reforms that are directly relevant to the data presented. Brief descriptions of the other reforms are given in Appendix A.

\section{Homework problems}

Problems were regularly assigned and graded. The problems assigned were not traditional end-of-chapter textbook exercises. Instead, they included a mix of challenging activi- ties including representation translation problems, contextbased reasoning problems, ranking tasks, estimation problems, and essay questions with epistemological content. (For more on these types of problems see Chap. 4 of Ref. 78.)

The instructor (Redish) expected that each problem would take the students about an hour to complete, and he communicated this expectation to the class. In accordance with his expectation, the instructor only assigned about five problems each week. (The specific problems we discuss here are given in Appendix B.) Because these problems were assigned as homework and graded, our observations of students working on these problems gave us an authentic look at how students actually behave in real-world problem-solving situations-as opposed to watching them solve problems artificially posed to them in an interview environment.

\section{Coherence}

An important characteristic of the reformed class was the attempt to make the various parts epistemologically oriented and mutually supportive. The instructor and the teaching assistants frequently cross-referenced among homework, lectures, tutorials, and laboratories. Exam questions drew from and mixed information that the students had worked on in each of the class components.

\section{Course center}

Since the traditional discussion sections were converted to tutorials, the students did not have time to discuss the problems on the homework set with a teaching assistant (TA) during these periods. To close this gap, a room was set up, called the course center, where students could gather to work on the homework problems together. The data reported on here come from videotaped sessions of students working on homework problems in the course center.

A TA or instructor was available in the course center approximately $20 \mathrm{~h}$ per week. The TA or instructor was present to offer assistance but not to explicitly solve the problems for the students, as they often do in many traditional recitation sessions. The relevant features of this room were its architecture, the white boards, and the audio-video setup.

\section{Architecture}

Many students expect recitation sessions in which a teaching assistant stands at the front of the room and solves problems, while the students frantically copy down the solutions. The architecture of the course center was altered to modify this expectation by removing the front of the room. All the chairs with desk arms were removed, and they were replaced with stools and five long workbenches. (See Fig. 7 for a schematic layout.) This seating arrangement did not direct the attention of the students to any one location in the room-as is the case in all lecture halls in which the seating is arranged to face the "front," directing attention to the lecturer. The natural focus of attention of a student seated at one of these worktables is the work area in front of them and the students seated across from them. 


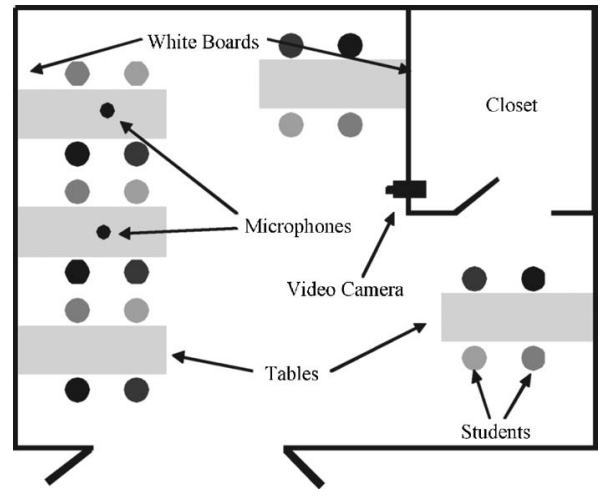

FIG. 7. Top view of the layout of the course center.

\section{Whiteboards}

As a second alteration to the course center, whiteboards were mounted on the walls and the students were provided with dry erase markers. The reason for this was threefold. First, the location of the whiteboards made them difficult to reach for the TAs but easy for the students - an architectural feature that encourages the students to go to the whiteboards and discourages the TAs from solving the problem for the student or "lecturing" at the whiteboards. Second, the whiteboards facilitate group problem solving. Research on expert and novice problem solving has shown that external representations are a helpful and sometimes necessary tool in the problem-solving process. ${ }^{24,31}$ The whiteboards offered the students a medium to share their external representations with each other. Third, the whiteboards helped with our research agenda. The students' shared representations on the whiteboards are visible to the video camera.

\section{Audio-video setup}

The course center was equipped with a digital video camera. Microphones were mounted in the middle of two tables to ensure quality audio reception. The video camera was mounted about $7 \mathrm{ft}$ above the floor on the wall of the closet across from the tables that were equipped with microphones. The elevation of the camera had three advantages:

- students and staff members walking by the closet did not block the camera;

- students sitting closer to the camera did not block our view of students who sat closer to the wall; and

- we had a clear view of what the students wrote on the whiteboards.

Students were encouraged to work at the two tables that could be recorded. At the beginning of a session, the camera was pointed at an occupied table and that microphone connected to the camera. Most students were willing to work at these tables and we have strong evidence that they quickly forgot they were being recorded.

\section{Methodology}

The data for this study come from about $60 \mathrm{~h}$ of videotaped sessions of groups of students solving homework prob- lems in the course center. Sixty h of video is too much to be analyzed in detail, so we selected promising episodes from the full data set. We looked for episodes rich in articulated student thinking and reasoning, and ones that contained some discussion of mathematical issues (qualitative or quantitative). These selection criteria reduced the data set to about $11 \mathrm{~h}$ of video that were analyzed in detail.

These $11 \mathrm{~h}$ of video were transcribed and analyzed. The games were determined by a semiphenomenographic approach. ${ }^{79}$ We identified video segments that appeared to contain students carrying out coherent and consistent activities (whether correct or not). The authors viewed these segments multiple times and identified plausible goals, moves, and exclusions. Hypotheses for specific games were proposed. During weekly meetings of the research team (the authors plus other members of the University of Maryland Physics Education Research Group), the transcription and coding of the episodes were scrutinized and the descriptions of the proposed e-games refined. Finally, two different coders independently analyzed a sample episode in terms of epistemic games, with an inter-rater reliability of $80 \%$. After discussion, the two codings were in complete agreement. The process resulted in the identification of the six games described in Sec. III.

\section{TWO CASE STUDIES}

We now present two case studies that demonstrate how an analysis in terms of resources and e-games can help make sense of student problem-solving behavior; in particular, why students often do not use what seems to the instructor to be the appropriate resources in a given context. The full transcripts of these episodes are included in Appendix A.

\section{A. Case 1: Building knowledge using e-games}

The episode for this case study involves three female students working on an electrostatics problem, which we refer to as the three-charge problem (Appendix B, Problem 1). ${ }^{80}$ This episode occurs in the second week of the second semester of a two-semester introductory, algebra-based physics course. All the students in the group had been in the reformed course the first semester and were familiar with its innovative features. In particular, they were familiar with the interaction style between students and teaching assistants in the course center and with the type of homework problems that were assigned in this course. Most importantly, they were cognizant of the fact that the instructor expected the students to spend about an hour on each homework problem-during which time they were expected to generate solutions to the questions that "made sense to them."

An "instructor's" solution to the three-charge problem involves straightforward balancing of forces and the use of Coulomb's law. The parenthetic comment in the problem states there is "no net electrostatic force" acting on charge $q_{3}$. Symbolically, this can be written as $\vec{F}_{q_{2} \rightarrow q_{3}}+\vec{F}_{q_{1} \rightarrow q_{3}}=0$. Manipulating this equation, and defining the positive $\hat{i}$ direction to be to the right, yields 


$$
\begin{aligned}
& \vec{F}_{q_{2} \rightarrow q_{3}}=-\vec{F}_{q_{1} \rightarrow q_{3}}, \\
& \frac{k q_{2} q_{3}}{d^{2}} \hat{i}=-\frac{k q_{1} q_{3}}{(2 d)^{2}} \hat{i} .
\end{aligned}
$$

Canceling similar terms on both sides of the equation and setting $q_{2}=Q$ yields the result $q_{1}=-4 Q$.

There are several inferences and steps involved in generating this solution. However, in spite of the multiple steps involved, most experienced physics teachers solve this problem in less than $1 \mathrm{~min}$. Some can "see" the answer in a conversational beat and give the correct answer immediately.

The most interesting aspect about the students' approach is that it takes so long. The students work for about $45 \mathrm{~min}$ before arriving at a solution-two orders of magnitude longer than the typical teacher! Why does it take so long? The typical teacher has a broader mathematical knowledge base (i.e., a larger collection of compiled mathematical resources) and richer collection of problem-solving strategies (i.e., an assortment of epistemic games for solving problems in physics) than most students. For the typical teacher, the problem statement immediately cues the appropriate epistemic game and tightly compiled resources; whereas, the students' mathematical resources do not exist in compiled form. The difference in the teacher and the students' knowledge structure could account for the difference in the speed of the problem solution and demonstrates the power and effectiveness of cognitive compilation. ${ }^{55}$

The students do not follow a straightforward approach to solving this problem. However, these students' various problem-solving approaches are readily understood in terms of epistemic games. We identify five different epistemic games that are played during this problem-solving session: Physical Mechanism, Pictorial Analysis, Mapping Mathematics to Meaning, Transliteration to Mathematics, and Mapping Meaning to Mathematics. We divide the discussion into segments corresponding to different e-games and refer to these segments as "strips." The names in the transcripts of the strips are gender-indicative pseudonyms.

\section{Playing the Physical Mechanism Game}

The students' initial attempt to solve this problem follows a less formal path than the instructor's solution outlined above. Throughout this strip the students draw on intuitive reasoning primitives to explain and support their conclusions. The students do not activate any formal mathematics or physics principles to support their claims. The reasoning consists almost entirely of facets. This first strip occurs about $7 \mathrm{~min}$ into the problem-solving process.

Darlene: I'm thinking that the charge $q_{1}$ must have it's...negative $Q$

Alisa: We thought it would be twice as much, because it can't repel $q_{2}$, because they're fixed. But, it's repelling in such a way that it's keeping $q_{3}$ there.

Bonnie: Yeah. It has to-
Darlene: $\quad$ Wait say that.

Alisa:

Like- $q_{2}$ is $-q_{2}$ is pushing this way, or attracting - whichever. There's a certain force between two $Q$, or $q_{2}$ that's attracting.

Darlene: $\quad q_{3}$.

Alisa: $\quad$ But at the same time you have $q_{1}$ repelling $q_{3}$.

Darlene initiates the conversation by asserting that the charge on $q_{1}$ must be "negative $Q$." The negative sign in this case standing for her realization that $q_{1}$ and $q_{2}$ will have opposite effects on $q_{3}$. Alisa elaborates on this point by articulating that $q_{2}$ exerts an influence on $q_{3}$, which she identifies as a force, that is either repelling or attracting, and that $q_{1}$ exerts the opposite influence on $q_{3}$. The semantic content contained in Alisa's explanation can be summarized in the following facet: "the attractive effect of $q_{2}$ on $q_{3}$ cancels the repulsive effect of $q_{1}$ on $q_{3}$." The abstract reasoning primitive underlying this facet is canceling. In this case, canceling is an appropriately mapped primitive, because in fact the two forces acting on $q_{3}$ do cancel, which results in there being no net electrostatic force on $q_{3}$.

From Alisa's initial cursory comment ("we thought [the charge on $q_{1}$ ] would be twice as much [as the charge on $q_{2}$ ]") it appears that she has the reasoning primitives more is more and balancing activated. That is, since the two influences acting on $q_{3}$ balance, $q_{1}$ must have more charge because there is more distance between $q_{1}$ and $q_{3}$ than there is between $q_{2}$ and $q_{3}$.

It cannot be confirmed whether Alisa has more is more and balancing activated, because the direction of the conversation changes. Darlene contends with the other students, because it appears she has activated a different reasoning primitive: blocking.

Darlene: How is it repelling when it's got this charge in the middle?

Alisa: Because it's still acting. Like if it's bigger than $q_{2}$ it can still, because they're fixed. This isn't going to move to its equilibrium point. So, it could be being pushed this way.

Darlene: Oh, I see what you're saying.

Alisa: Or, pulled. You know, it could be being pulled more, but it's not moving.

Darlene: Um-huh.

The orientation of the charges cues the reasoning primitive of blocking, because $q_{2}$ is between $q_{1}$ and $q_{3}$. From the superposition principle we know the effect of $q_{1}$ on $q_{3}$ does not get blocked by the presence of $q_{2}$, so the activation of blocking is an unnecessary distraction. In contrast to the reasoning primitive of canceling that was activated earlier in this strip, blocking does not get mapped into a productive facet for solving this problem. (This is not to say that blocking is "wrong;" rather, in this particular instance the activation of blocking does not lead to a productive facet.) 
Bonnie continues Alisa's line of reasoning by explaining why the value of $q_{1}$ has to be twice as big as that of $q_{2}$.

\begin{tabular}{|c|c|}
\hline Alisa: & $\begin{array}{l}\text { So, we-we were thinking it was like negative } \\
\text { two } Q \text { or something like that. }\end{array}$ \\
\hline Bonnie: & $\begin{array}{l}\text { Yeah. Cause it has to be like big enough to } \\
\text { push away. }\end{array}$ \\
\hline Darlene: & Push away $q_{3}$. \\
\hline Bonnie: & $\begin{array}{l}\text { Yeah, which we-which I figured out negative } \\
\text { two. }\end{array}$ \\
\hline Darlene: & $\begin{array}{l}\text { Cause it's twice the distance away than } q_{2} \\
\text { is? }\end{array}$ \\
\hline Bonnie: & Yeah. \\
\hline Darlene: & I agree with that. \\
\hline
\end{tabular}

It appears that Alisa draws on overcoming when she explains that "Like if it's bigger than $q_{2}$ it can still [have an effect]" and Bonnie restates this as " $\left[q_{1}\right]$ has to be like big enough to push away $\left[q_{3}\right]$." That is, $q_{1}$ has to have enough charge to overcome the influence of $q_{2}$. The tacit conclusion from this assertion is that the charge of $q_{1}$ must have a larger magnitude than that of $q_{2}$. This is particularly interesting since Alisa later shows (see below) that she understands Coulomb's law and superposition. But in the context of Physical Mechanism she generates an (incorrect) argument in support of her sense that the force from both source charges must be included using reasoning primitives and facets. This is a clear example of the e-game she is playing limiting the responses that she considers appropriate within the context of this particular game.

Bonnie and Darlene quantify this conclusion by using the reasoning primitive more is more and the symbolic form dependence (which has the symbol template $\square=[\ldots x \ldots]$ ) to assert that the charge on $q_{1}$ has to be twice the magnitude of $q_{2}$. More is more and dependence get mapped into the facet twice the distance is twice the charge. Bonnie's argument stays within the rules of the local e-game. Because physical mechanism does not include moves that access formal knowledge, they do not invoke the formal knowledge that says blocking is irrelevant. We will see later that they (and Alisa in particular) indeed do have the relevant formal knowledge.

The students' problem-solving activities during this entire strip have the ontology of Physical Mechanism. While playing this game the students draw on their intuitive knowledge base rather than their formal knowledge to support their claims. During this strip the students use various reasoning primitives and do not mention any formal mathematics or physics principles. The epistemic form in the Physical Mechanism Game involves a coherent, physical description that is either verbal or imagistic. These students are actively seeking physical causes for the effects that are described in the problem.

Playing this game helps the students become oriented to this problem, but the solution to this problem necessarily involves physics equations (in particular Coulomb's law). Since Physical Mechanism does not include mathematical expressions or equations, it cannot ultimately lead them to the correct answer. In the next strip, a comment from the TA helps them reframe the problem, which activates other resources they have, and cues them to play another epistemic game.

\section{Playing the Pictorial Analysis game}

In the last strip we saw the students making sense of the problem by using their intuitive reasoning primitives in the context of Physical Mechanism game. At the end of the strip, the students appear to have difficulty focusing their collective attention. Although they achieve the correct conclusion (which forces are relevant to consider), a question asked by one of them causes the others to begin the discussion anew, losing the ground they had gained through the discussion. ${ }^{81}$ This happens twice. To assist them, the TA (Tuminaro) offers a suggestion.

Darlene: I think they all have the same charge.

Bonnie: You think they all have the same charge? Then they don't repel each other.

Darlene: Huh?

Bonnie: $\quad$ Then they would all repel each other.

Darlene: $\quad$ That's what I think is happening.

Bonnie: $\quad Y e a h$, but $q_{3}$ is fixed. If it was being repelled-

Alisa: $\quad$ No, it's not. $q_{3}$ is free to move.

Bonnie: $\quad I$ mean, $q_{3}$ is not fixed. That's what I meant.

Darlene: Right.

Bonnie: So, like...

Darlene: $\quad$ So, the force of $q_{2}$ is pushing away with is only equal to $d$.

Bonnie: Yeah, but then..

Darlene: $\quad$ These two aren't moving.

Bonnie: Wouldn't this push it somewhat?

Alisa: $\quad J u s t$ because they're not moving doesn't mean they're not exerting forces.

Darlene: $\quad$ I know.

Alisa: $\quad$ What do you think?

TA: $\quad$ Can I make a suggestion?

Darlene: Uh-huh.

TA: $\quad$ You guys are talking about like a lot of forces and stuff. And, one thing I've suggested in previous semesters, if you write it down and say, what forces do you think are acting here, you can all talk about it.

Darlene: Where did the marker go?

TA: $\quad$ That's a suggestion-a general suggestionthat I might make.

In the first few lines above, it seems as though the students take a step back. Earlier, they appeared to have established the major aspect of the problem: two influences act on $q_{3}$, which exactly cancel each other. In this strip, the students restate the setup of the problem ("these two aren't moving") and recite remembered facts ("just because they're not moving doesn't mean they're not exerting forces"). While these 
things are important to keep straight, this discussion does not appear to push the problem-solving process forward.

The suggestion to write on the whiteboards has two effects on the students. First, it nudges them into playing a different epistemic game, Pictorial Analysis. ${ }^{82}$ Second, the introduction of this new epistemic game and a new e-form reframes the students' interactions and helps them focus their collective attention and clarifies their communication.

Alisa attempts to make an external representation of this problem on the white board while Bonnie and Darlene offer their assistance:

Darlene: $\quad Y o u$ 're trying to figure out what $q_{1}$ is, right? Bonnie: Oh, yeah.

Alisa: Because this $\left[q_{3}\right]$ is in equilibrium, there's some force...

Darlene: $\quad$ Pulling it that way and some force pulling ex-equally back on it.

Bonnie: Yeah.

Alisa: $\quad$ And, they're equal?

Bonnie: Yes.

Darlene: $\quad$ Same with up and down. Not that that matters, really.

Bonnie: We'll just stick with...

Darlene: Horizontal.

Bonnie: $\quad Y e a h$, one dimension.

In this strip the students are deciding which features mentioned in the problem should be included in their diagram-a move within Pictorial Analysis. The structure of this game is similar to Physical Mechanism; however, the ontological components of Physical Mechanism and Pictorial Analysis are different. The epistemic form in Pictorial Analysis involves a coherent, physical description and an external representation; the epistemic form for Physical Mechanism only involves a coherent, physical description.

The external representation generated in the Pictorial Analysis epistemic game activates additional resources in the students, which help them better understand this problem. In particular, the students draw on the interpretive device of physical change to conclude that $q_{1}$ and $q_{2}$ have to have opposite charges.

Alisa: $\quad$ So, maybe this is pushing...

Darlene: That's $\left[q_{2}\right]$ repelling and $q_{1}$ 's attracting?

Bonnie: Yeah, it's just that whatever $q_{2}$ is, $q_{1}$ has to be the opposite. Right?

Alisa: $\quad$ Not necessarily.

Darlene: Yeah.

Bonnie: $\quad O K$, like what if they were both positive?

Alisa: Well, I guess you're right, they do have to be different, because if they were

both positive...

Bonnie: $\quad$ Then, they'd both push the same way.

Alisa: $\quad$ And, if this were positive it would go zooming that way.

Darlene: $\quad$ They would both push.

Alisa: And, if this were negative it would go there.

Bonnie: It would go zooming that way.

Alisa: $\quad$ And, if they were negative...

Darlene: It would still-they'd all go that way.

Alisa: It would be the same thing.

Bonnie claims that the charge on $q_{1}$ has to be the opposite of $q_{2}$, but the other students do not initially agree, despite the fact that this claim was agreed upon in the context of a different game in the previous strip. Bonnie's suggestion to verify, or falsify, her claim involves the interpretive strategy of physical change. That is, she considers the effect of an actual physical alteration to the system ("OK, like what if they were both positive?"). From this move the students almost immediately conclude that the charges on $q_{1}$ and $q_{2}$ must be different, or else $q_{3}$ would go "zooming" away, since both forces would push in the same direction.

Switching to Pictorial Analysis turns out to be a very effective strategy for this group of students. By decomposing the forces in space and creating an external representation, they are able to physically justify why $q_{1}$ and $q_{2}$ have to have opposite charges. This strip also illustrates that the students' problem does not stem from lack of knowledge or skills; rather, the epistemic game the students play in their initial approach (Physical Mechanism) does not help them adequately articulate the physical relationship between the charges. The external representation they collectively generate in Pictorial Analysis cues resources they already possess (physical change), which helps them make progress on this problem (i.e., conclude with confidence that $q_{1}$ and $q_{2}$ have opposite charges).

Although the students' external representation and conclusion marks progress, they have yet to solve the problem. In fact, they have not even identified the necessary physics principle (Coulomb's law), which is what happens in the next strip.

\section{Playing the Mapping Mathematics to Meaning game}

So far the students have drawn a diagram representing which forces act and in what direction; and they have concluded that $q_{1}$ and $q_{2}$ have opposite charges. However, they have not yet solved the problem. In this strip we see Alisa spontaneously reframe the problem-solving process by drawing on a new set of resources: formal mathematics knowledge.

Alisa

Bonnie:

Darlene:

Alisa:

Bonnie:

Alisa:

Bonnie:
Are we going to go with that? [That $q_{1}$ is twice as big as $q_{2}$ and opposite.]

I think it makes sense.

That makes...

Well, I don't know, because when you're covering a distance you're using it in the denominator as the square.

Oh! Is that how it works? And (?) makes a difference. Yeah, you're right. 
TA:

All:

Bonnie:

Alisa:

Alisa is not only attempting to introduce an equation, she is negotiating a shift in how this problem is being viewedasking the group to play a new epistemic game. All the previous reasoning relied on intuitive reasoning primitives, without any explicit reference to physics principles or equations. Alisa's introduction of Coulomb's law is the first mention of a physics principle during this entire problem-solving process. In addition, it is the first time anyone explicitly makes reference to an equation ("when you cover a distance you use it in the denominator as the square"). Alisa's use of formal physics principles and explicit reference to equations is (tacitly) asking the other students to play Mapping Mathematics to Meaning.

Alisa's discussion follows all the moves within Mapping Mathematics to Meaning (see Fig. 8). First, the distance and force are identified as the relevant concepts in this problem. Second, she identifies Coulomb's law $\left(F=\frac{k q_{1} q_{2}}{r^{2}}\right)$ as an equation that relates the target concept to other concepts. Third, she develops a story using this relationship between concepts: "When you're covering a distance you're using it in the denominator as the square." Fourth, she evaluates the validity of her story by referencing a previous problem. She acknowledges that her intuitive reasoning had failed her on

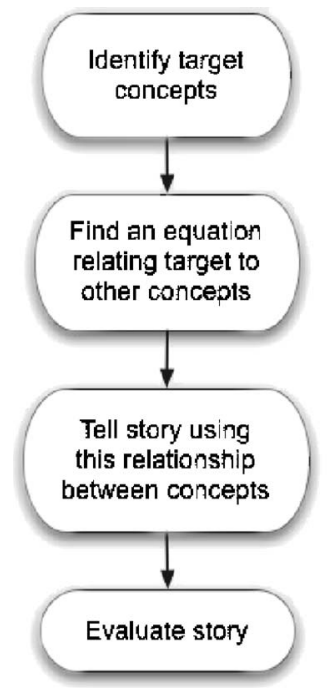

Distance and force

$$
F=\frac{k q_{1} q_{2}}{r^{2}}
$$

"...when you're covering a distance, you're using $\mathrm{it}$ in the denominator as a square

\section{"Cause we were getting} into problems in the beginning of the problem with [problem $2 \mathrm{~A}$ ]"

FIG. 8. Schematic map of Alisa's moves within Mapping Mathematics to Meaning. the previous problem, which justifies for her the need for Coulomb's law on this problem: "I thought that like if you move this a little bit to the right the decrease for this would make up for the increase for this. But, then we decided it didn't."

Alisa's use of Coulomb's law is significant progress on this problem, but all the other students do not know how to apply this new piece of information. In fact, the introduction of Coulomb's law cues Darlene to play a new (and counterproductive) epistemic game.

\section{Playing the Transliteration to Mathematics Game}

Although it appears the students are making progress on this problem, they take a detour and attempt to use another problem as a prototype for solving this problem. Alisa has suggested that Coulomb's law is an important concept. It appears that Darlene does not initially know how to apply this new information. She attempts to find a different problem that uses Coulomb's law in its solution, and then map the solution pattern from the other problem to the threecharge problem. The problem that Darlene identifies as using Coulomb's law in the solution is the two-charge problem (Appendix B, problem 3).

Darlene: Where is that other problem? Three times as far apart as they were now what is the magnitude of the force?

Bonnie: I think it should be four times.

Darlene: If it's three times as far apart it's...you divide...uh! I think it's q over two.

Bonnie: $\quad q$ over two? So, if you think of it as half the force of $q_{2}$.

Darlene: Look at this one.

Bonnie: Is this one you're talking about?

Darlene: Uh-huh. If you increase the distance that they are from each other it's

decreasing by the same amount. I thought it was four (?), but they said it was

(?). I don't know why. Just three times...does it matter? I'm looking at this one. Number three, isn't that like the same thing?

Alisa: $\quad$ Three was an estimation problem.

Darlene: No, no with the $q$ and four $q$ and all that, you know how there was this question that asked when you move the charges three times further apart than they originally were, what the resulting force is.

Alisa: $\quad O K$.

Darlene: $\quad$ And, you said it was-we said it was fourthe charge would be like q, or nine, but it would get three times as far apart. Why it's not three I don't understand, but that's all right. So- 
Alisa:

Well, 'cause in the equation you square

this-the distance between them. Like

if you're multiplying by three...

Darlene: $\quad$ Oh! So, I would think this one would be q over four-negative q over four.

Cause it's twice as far away, opposite charge. Does that make sense?

Alisa: $\quad$ But, then it's a smaller charge than this.

Bonnie: Yeah.

Alisa: $\quad$ So, I don't understand how it would be pushing three or pulling three whatever it's doing.

In the force-distance two-charge problem, the students had found that if the force between two charges for a given distance is $F$, tripling the distance results in a force between the two charges that is decreased by a factor of 9 (see Appendix B, problem 3), in compliance with Coulomb's law. Darlene is attempting to match the quantities in the three charge problem with quantities from the force-distance charge problem, so the solution pattern can be transferred, i.e., she is playing the Transliteration to Mathematics epistemic game.

One piece of evidence that Darlene is playing Transliteration to Mathematics comes when she says, "Why it's not three I don't understand, but that's all right." Darlene is explicitly indicating that she does not understand the previous problem, but conceptual understanding is not a move in the Transliteration to Mathematics epistemic game. All that is important is that the problems have enough similar features that the solution from one problem can be transferred to the other.

Darlene's metacognitive statement ("Why it's not three I don't understand, but that's all right.") stands in stark contrast to Alisa's metacognitive statement ("I thought that like if you move this a little bit to the right the decrease for this would make up for the increase for this."). Darlene simply admits she does not understand and slavishly transfers the solution pattern from the previous problem anyway. In contrast, Alisa's metacognitive statement leads to her justification for using Coulomb's law.

Darlene's Transliteration to Mathematics approach does not help her with the three-charge problem. She says, "If you increase the distance that they are from each other it's decreasing by the same amount." The problem with Darlene's approach is that she is unaware of the two meanings that she attributes to the pronoun "it." In the previous problem the pronoun stands for "force," so that the statement would read, "If you increase the distance that they are from each other, then the force is decreasing by the same amount." However, Darlene tacitly maps this into the statement, "If you increase the distance that they are from each other, then the charge is decreasing by the same amount." The Transliteration to Mathematics game is not helpful in this case because force and charge are not related to distance in the same way in Coulomb's law. The charge has to be found from the balance of two forces. This is not to

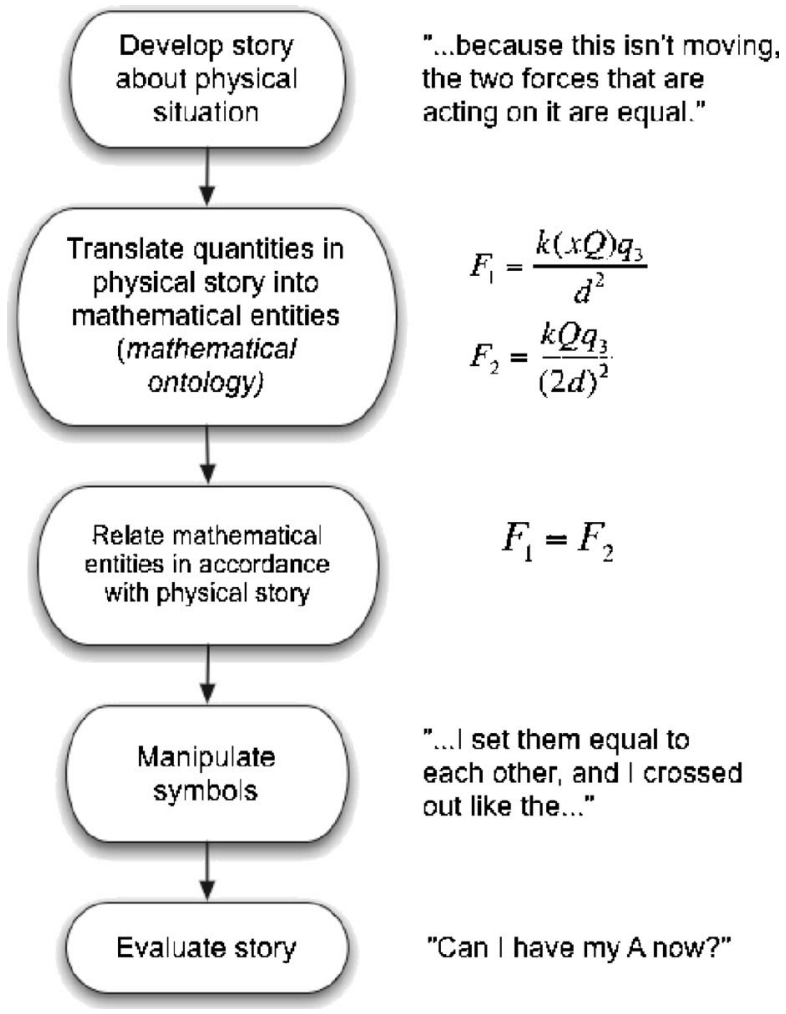

FIG. 9. Schematic map of Alisa's moves within Mapping Meaning to Mathematics.

say that the Transliteration to Mathematics game is wrong. Rather, it does not work in this situation because of Darlene's inappropriate mapping of force and charge. The components (ontology and structure) of Transliteration to Mathematics can also be found as a part of the richer Mapping Mathematics to Meaning game- just as is true for Recursive Plug-andChug, but the goals (perceived end states) of the games differ.

\section{Playing the Mapping Meaning to Mathematics Game}

In this strip the students finally come to the solution of the problem. Alisa summarizes her final solution as the other students listen. Alisa's problem-solving activities follow the Mapping Meaning to Mathematics epistemic game (see Fig. 9). First, she develops a conceptual story describing the physical situation. This conceptual story relies heavily on the reasoning primitives of balancing.

TA: What did you do there?

Alisa: $\quad$ What did I do there?

TA: Yeah, can I ask?

Alisa: $\quad$ All right, so because this isn't moving, the two forces that are acting on it are equal: the push and the pull.

Alisa correctly maps force as the two influences that balance in this physical situation. Second, Alisa uses the idea of identity (a symbolic form, ${ }^{6}$ with the symbol template $=\cdots)$ to translate her conceptual story into mathematical expressions: 
Alisa:

So, the F-I don't know if this is the right $F$ symbol-but, the $F q_{2}$ on $q_{3}$ is equal to this [see Eq. (2)]. And, then the $F q_{1}$ on $q_{3}$ is equal to this [see Eq. (3)], because the distance is twice as much, so it would be four $d$ squared instead of $d$ squared.

$$
\begin{gathered}
F_{q_{2} \rightarrow q_{3}}=\frac{k Q q_{3}}{d^{2}}, \\
F_{q_{1} \rightarrow q_{3}}=\frac{k x Q q_{3}}{4 d^{2}} .
\end{gathered}
$$

Alisa explains why she wrote the charge on $q_{1}$ as " $x Q$," by drawing on the reasoning primitive of scaling (another symbolic form, ${ }^{6}$ this one with the syntax $x \square$ ).

Alisa:

$$
\begin{aligned}
& \text { And, then I used } x Q \text { like or you can even } \\
& d o-y e a h-x Q \text { for the charge on } q_{1} \text {, } \\
& \text { because we know in some way it's going to } \\
& \text { be related to } Q \text { like the big } Q \text { we } \\
& \text { just got to find the factor that relates to that. }
\end{aligned}
$$

In the third step in the Mapping Meaning to Mathematics, Alisa relates the mathematical entities that she derived in step 2 with her conceptual story that she developed in step 1:

Alisa: $\quad$ Then, I set them equal to each other... Fourth, she manipulates the mathematical expression to arrive at the desired solution:

Alisa: $\quad \quad \ldots$ and I crossed out like the $q_{2}$ and the $k$ and the $d$ squared and that gave me $Q$ equals $x Q$ over four. And, then $Q$ equals four $Q$, so $x$ would have to be equal to four. That's how you know it's four $Q$.

Fifth, the other students evaluate Alisa's problem-solving approach and conclusion.

Bonnie: Well, shouldn't it be-well equal and opposite, but...

Alisa: $\quad Y e a h$, you could stick the negative.

Bonnie: Yeah.

Darlene: I Iidn't use Coulomb's equation, I just-but it was similar to that.

Bonnie: $\quad$ That's a good way of proving it.

Darlene: Uh-huh.

Bonnie: Good explanation.

Alisa: $\quad$ Can I have my A now?

Darlene and Bonnie accept Alisa's approach is "a good way of proving it." In fact, Alisa must realize that this is a good way to prove this, since she self-evaluates her solution and asks for an "A now."

\section{B. Case 2: Playing Recursive Plug-and-Chug}

In our second case study, a group of three students is attempting to solve the air pressure problem (Appendix
$\mathrm{B}$, problem 4). The episode occurs near the end of the first semester of the class. The problem is a fairly straightforward estimation problem in which the students have to come up with numerical data on their own from their personal experience. There has been such a problem on nearly every homework assignment and on every exam throughout the semester. Nonetheless, some students bring into the class what appear to be quite robust "misconceptions of expectations" and have considerable difficulty in getting into the spirit of estimation problems. For most of the recorded episode, one student (code named Susannah) dominates the discussion. Part way into the episode, a teaching assistant attempts to help get her on the right track.

An instructor's solution to this problem is straightforward. The problem asks the student to estimate the pressure difference between the floor and ceiling of their dorm room. The equation that governs the pressure difference is

$$
p_{\text {floor }}-p_{\text {ceiling }}=\rho g h,
$$

where $\rho$ is the density of the air, $g$ is the gravitational field constant $(\sim 10 \mathrm{~N} / \mathrm{kg})$, and $h$ is the height of the ceiling above the floor. The value of $h$ can be easily estimated by knowing your own height, visualizing yourself in your dorm room, and estimating how many times taller than yourself the ceiling is. A reasonable height for many rooms is $3 \mathrm{~m}$. Putting this together with the density of the air (given as $\sim 1 \mathrm{~kg} / \mathrm{m}^{3}$ ) gives the result

$$
\begin{aligned}
p_{\text {floor }}-p_{\text {ceiling }} & \approx\left(1 \mathrm{~kg} / \mathrm{m}^{3}\right)(10 \mathrm{~N} / \mathrm{kg})(3 \mathrm{~m}) \\
& =30 \mathrm{~N} / \mathrm{m}^{2}=30 \mathrm{P} .
\end{aligned}
$$

The solution appears quite straightforward-if you choose the correct equation and if you use your own experience as a source of quantitative data. The student in this episode does neither.

At the beginning of the episode, we transcribe the following interesting strip.

Martha: We're saying that the pressure...

Susannah: Right.

Martha: Well pressure's supposed to be higher at the bottom, isn't it?

Susannah: Hmm?

Martha: $\quad$ Pressure is supposed to be higher at the bottom.

Susannah: I think there's more at the bottom, because the thing, because the gravitation.

Martha: And, there's pressure pushing down on it. Susannah: Um-huh.

Martha: $\quad O K$. 
Susannah: Pressure's equal to the radius times the moles of the gas times the temperature divided by the volume. So, what we need to do, we know the pressure find the volume from this. Density is equal to...

Martha: $\quad$ Are you using $p V$ equals $n R T$ ?

Susannah: Huh?

Martha: $\quad$ Are you using $p V$ equals $n R T$ ?

Susannah: Yeah, or yeah.

Martha: $\quad O r$.

Susannah: $\quad$ Or $p$ equals $R$ times $n T$...

Martha: Over $V$.

Susannah: Over $V$.

What's going on in this exchange can be nicely described in terms of e-games. Martha begins with a statement that proposes they play an e-game involving mechanism and a qualitative story, perhaps Physical Mechanism. We cannot say for sure, since Susannah quickly makes a move to establish a different e-game, one that, it soon becomes clear, is Recursive Plug-and-Chug. Her choice of the form of the law $(p=n R T / V)$ suggests that she began with the identification of a variable-the pressure, rather than the pressure difference. And she knows an equation containing that variable - the ideal gas law.

The next strip is also remarkable.

Susannah: $\quad O K$. So, if let's say it's [the density] equal to mass over volume, then [to another student] yeah. No I just found the formula to do it. So, this is equal to mass over volume, then the mass is equal to... So, basically we just found the formula that $p$ is equal to the radius times the moles times the temperature over the volume. So, if we have the density we can find the volume.

Martha: $\quad I s$ the radius?

Daphne: I don't think $R$ is the radius.

Susannah: It's not? The radius of the...

Martha: $\quad R$ isn't radius. $R$ is...

Susannah: $\quad O r$, whatever $R$ is.

Daphne: Some number.

Martha: It's not radius.

Susannah: Is it a constant?

Alice: $\quad Y e a h$, it's a constant. It's a constant.

Martha: $\quad$ It's a constant. It's...

Susannah: Awesome. One less thing for us to find.

Susannah has focused on the fact that the density is given and is trying to use that number to generate the value of other unknowns in her formula. She admits to being deeply mistaken about the meaning of one of the symbols in her equation ("It's not? The radius of the...?"). This doesn't bother her; on the contrary, she is very pleased ("Awesome. One less thing for us to find."). This is strong evidence that she is playing Recursive Plug-and-Chug, an e-game with a strict and very limited set of allowed moves. It is not an admissible move in this game to evaluate whether the equation makes sense in terms of mechanism, and (as we see below), it is not an admissible move to get quantitative information from anywhere but an authoritative source tied to the class.

After some discussion, Susannah and Martha have decided that they need to find the volume of the dorm room. The TA is passing by and in the next strip they ask for help. He asks how far they have gotten and they explain their position. Following the guiding principles we set down for TAs, he does not tell them they have the wrong equation. Rather, he encourages them to reason it through fully. Susannah decides she knows both the mass and the volume of the dorm room.

Susannah: Well, it's one kilogram per for meters cubed, so it's kind of easy.

TA: $\quad$ That's the density?

Susannah: Yeah, but that's kind of giving it to us easy, right, cause it's...

Martha: It's saying that mass is one, one kilogram. Is that what you're saying?

Susannah: One kilogram per one meter cubed.

TA: Right, so if you lived in a room that was this big [he gestures in space describing a one meter cube], one meter cubed there would be one kilogram of air there.

Susannah: Yeah.

TA: I don't think you live in a room that big.

Susannah: Yeah, I feel silly. OK. So, it's one kilogram...

TA: $\quad$ So, what um...

Martha: So, the mass is one kilogram, is what you're saying?

TA: $\quad$ Would you agree with me this is an estimation problem?

Susannah: $\quad U m$.

Martha: Yes.

TA: $O K$.

Susannah: $\quad$ To a certain extent, yeah.

TA: $\quad$ What this problem is about a dorm room. How big is a dorm room?

Susannah: Oh!

Martha: Not big at all.

Susannah: He gave it in another problem. Like another homework.

In this strip, Susannah shows serious resistance to the idea that the data she is to use in a physics problem can come from her own experience. ${ }^{83}$ In watching the video, her facial expressions, cadence, intonation, and body language give clear clues to what she is thinking. At the beginning of the strip, she feels that she has found the answer-there is a mass and a volume given in the problem that she has overlooked: the density (of air) is specified as a mass over a volume. Since she appears to be looking for a number given 
in the problem and since interpretation of the number is not an allowed move in her e-game, she is satisfied with finding a mass $(1 \mathrm{~kg})$ and a volume $\left(1 \mathrm{~m}^{3}\right)$. Indeed, she comments, "it's kind of easy." Her later statement "I feel silly" does not appear to be in response to the TA's statement, "I don't think you live in a room that big." On the contrary, she appears to be ignoring the TA and not attending to his statement at all. This is confirmed by her immediate continuation (without a pause), "so it's 1 kilogram...." The TA, apparently realizing that Susannah is not thinking about a dorm room at all but just looking for numbers tries to get her to play the right game by saying, "Would you agree with me that this is an estimation problem?" Susannah, apparently not fully attending to the question, looks up and makes a noncommittal sound. Martha quickly and firmly agrees. In response to further pressure, Susannah suggests they look back in their notes for previous information.

Susannah's response to, "How big is a dorm room?" is "He gave it in another problem," and she starts to look in her notebook. This response makes no sense unless we accept the idea that Susannah is operating under a particular pair of local rules: All information to be used in a problem must come from a course-related authority and it is not necessary (or even allowed) to think about what is going on in terms of mechanism or conceptual story. Susannah is stuck playing Recursive Plug-and-Chug and even specific hints from the TA are ignored in this context.

\section{What we learn from these case studies}

These two studies are reasonably typical of the $11 \mathrm{~h}$ of video that we have studied of students in algebra-based physics class authentically solving physics problems. They demonstrate two points.

First, this population of students often works on problems within an invisible and often unstated web of constraining expectations we refer to as epistemic games. These expectations limit the resources these students are willing to use at a given time in the context of a given task. This limitation is in itself neither good nor bad. One cannot access all one's knowledge at any given time. One must restrict to a set of tools appropriate to the given task.

Second, a problem does arise when a student's perception of the tools appropriate to the task are not what we intend as instructors. If we only consider the epistemic form-a derivation, say, of an equation or result- and not the intuitive sense-making the instructor expects to go on behind it, we can be misled as to what the students are doing and the students can misinterpret what we are trying to teach. They wind up learning to play the wrong game.

The study reported in this paper focuses on students at the university level and most of them were upper division students who had already taken many science courses at the university. As a result, we make no claims concerning the origin of the games the students were playing. However, we often saw students playing games that were clearly learned somewhere. Students playing Recursive Plug-and-Chug, for example, had a very strong sense of what they thought they were supposed to be doing-both the goals of their local activities and what they ought to be doing to get there. We can well imagine the students being taught to "identify the variable to be found," to "find an equation containing that variable," and so forth. This strongly suggests that we need to be aware that when we are teaching our students processes that can produce effective results in situations with a particular limited class of problems to be solved, we may also unintentionally be teaching them to play particular epistemic games without helping them to develop a good sense of when those games might (or might not) be appropriate. Such instruction might help students get through the vicissitudes of a particular course but might have unintended negative consequences at later stages in the students' education.

\section{IMPLICATIONS FOR INSTRUCTION, AND CONCLUSIONS}

Far too often in physics instruction, physics teachers focus on the content and the answers to physics problems rather than on how to think about physics and how to solve problems effectively. When we choose our content as learning Newton's or Kirchoff's laws, when we give students a syllabus consisting of particular chapters in an encyclopedic text, and when we permit them to take a card consisting of all the "necessary equations" into an exam, we are sending an unintended message that what matters in physics are the equations and answers rather than the processes of generating and evaluating them.

Physics teachers generally know that this is not the case and may stress understanding and reasoning in their lectures. But students may not understand what this means. They may ignore the derivations and reasoning the teacher presents, box the final results in their notes for memorization, and ignore the process that generated them.

Research in physics education documents that students bring understandings of the physical world into their physics class that may contradict and confound their attempt to make sense of what is being taught. This can lead them to emphasize memorization-which in some environments works even when you have little understanding of what you are memorizing.

Physics teachers often have the sense that "problem solving is where you learn to actually do physics"-where students should learn the process and sense-making that exemplifies good physical thinking. We assign many problems and in our lectures we model the processes we want our students to follow. But until we have a good understanding of what kinds of thinking the students need to activate for solving problems, it is difficult to understand why some students seem to get so little out of solving large numbers of problems. ${ }^{84}$

As experts, our knowledge exists in compiled and wellstructured form, whereas the students' knowledge does not. As instructors, we may not be aware of all the knowledge and reasoning that goes into solving a problem, if we can see the solution easily and quickly. Decomposing students' problem-solving sessions in terms of epistemic games and resources allows us to "see" and examine the knowledge and reasoning that is involved in solving a problem in more de- 
tail. With increased understanding of the knowledge and reasoning involved in a seemingly simple problem, we can begin to develop teaching environments and interventions that more effectively and efficiently cue the appropriate resources and epistemic games. This in turn could help students become better and more efficient problem solvers.

The study reported on here gives two examples of how cognitive modeling helps increase our understanding of what our students need to learn. The specific resources and games we describe are not the only ones students use or play. Our intention is to introduce a new kind of structure for analyzing students' thoughts on problem solving. In addition, we have studied a particular population in a particular course. Further research is needed to determine whether the games that we have observed to be common among our students occur commonly among other student populations. Although it is true that, in the end, an epistemic game lives in the head of an individual student, and therefore each student may possess a unique set of games, we expect that, since many students experience similar learning environments, a limited set of games will prove useful in describing significant elements of the behavior of large numbers of students.

Our focus has been on structures in the cognitive model of the individual student, but it is clear that two additional factors play essential roles and also require further research. First, the student's decisions (tacit or conscious) about which games to play have a critical role. Second, the interaction of the students in their group games is extremely important and the structures proposed here could be of considerable help in understanding a group's negotiation of how to approach and solve a problem. We expect that the description of student problem solving behavior in terms of epistemic games will be useful both in understanding how to teach strategies and metacognition in problem solving and in analyzing group behavior in the context of problem solving.

\section{ACKNOWLEDGMENTS}

We are very grateful to the members of the University of Maryland Physics Education Research Group, many of whom contributed extensively to the discussions and analyses of these video strips. Particular thanks are due to Rachel Scherr who worked quite closely with us on some of these issues. We also thank Ginny Redish for extensive editorial suggestions. We also would like to acknowledge some particularly useful suggestions made by a set of anonymous referees. This work was supported in part by grants from the U.S. National Science Foundation, Grants No. REC-0087519, No. REC-04-40133, and No. DUE-05-24987.

\section{APPENDIX A: DESCRIPTION OF COURSE REFORMS}

See separate online auxiliary material for brief descriptions of

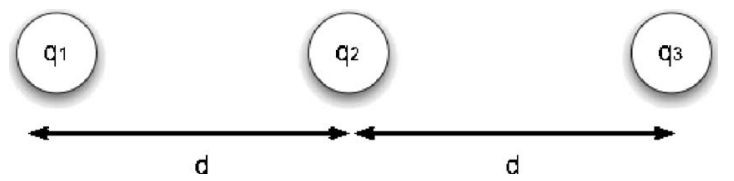

FIG. 10. Figure for the three-charge problem.

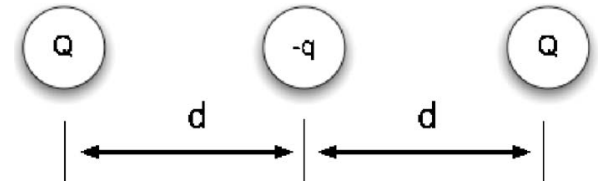

FIG. 11. Figure for the two-dimensional three-charge problem.

the other reforms as well as the full transcripts of the casestudy episodes.

\section{APPENDIX B}

\section{Three-charge problem}

In Fig. 10 three charged particles lie on a straight line and are separated by distances $d$. Charges $q_{1}$ and $q_{2}$ are held fixed. Charge $q_{3}$ is free to move but happens to be in equilibrium (no net electrostatic force acts on it). If charge $q_{2}$ has the value $Q$, what value must the charge $q_{1}$ have?

\section{Two-dimensional three-charge problem}

Suppose you have a particle with a negative charge $-q$ exactly between two identical particles with equal, positive charge $Q$, as shown in Fig. 11.

A. If you moved the particle in the middle a tiny bit to the right, what direction would the total force be on it by the other two charges?

B. Start with that particle back dead center again, and now move it a tiny bit up. In what direction would the total force be?

\section{Two-charge problem}

Two small objects each with a net charge of $Q$ (where $Q$ is a positive number) exert a force of magnitude $F$ on each other (see Fig. 12) ${ }^{85}$ We replace one of the objects with another whose net charge is $4 Q$. If we move the $Q$ and $4 Q$ charges to be three times as far apart as they were, what is the magnitude of the force on the $4 Q$ ? (a) $F / 9$; (b) $F / 3$; (c) $4 F / 9$; (d) $4 F / 3$; (e) other.

\section{Air-pressure difference problem}

Estimate the difference in pressure between the floor and the ceiling in your dorm room. (Note: You may take the density of air to be about $1 \mathrm{~kg} / \mathrm{m}^{3}$.)
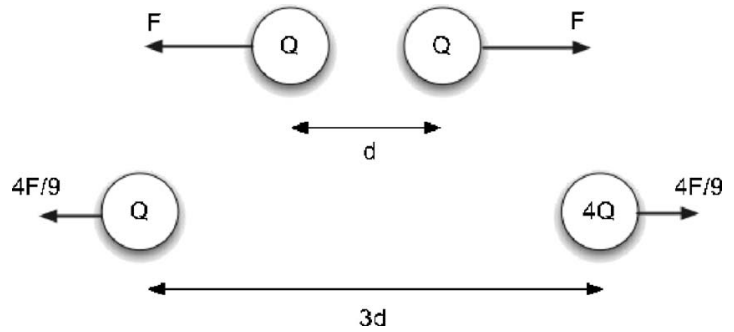

FIG. 12. Figure for the two-charge problem (with the answer shown). 
*Author to whom correspondence should be addressed. redish@umd.edu

${ }^{1}$ D. P. Maloney, Research on problem solving, in Handbook of Research on Science Teaching and Learning, edited by D. L. Gabel (Simon \& Schuster, MacMillan, New York, 1994), pp. 327-354; L. Hsu, E. Brewe, T. M. Foster, and K. A. Harper, Resource Letter RPS-1: Research in problem solving, Am. J. Phys. 72, 1147 (2004).

${ }^{2}$ Learning How to Learn Science: Physics for Bioscience Majors, NSF Grant No. REC-008-7519.

${ }^{3}$ A. diSessa, Towards an Epistemology of Physics, Cogn. Instruct. 10, 105 (1993)

${ }^{4}$ B. Sherin, The Symbolic Basis of Physical Intuition: A study of two symbol systems in physics instruction, Ph.D. dissertation, University of California, Berkeley, 1996.

${ }^{5}$ A. diSessa and B. Sherin, What changes in conceptual change?, Int. J. Sci. Educ. 20, 1155 (1998).

${ }^{6}$ B. Sherin, How Students Understand Physics Equations, Cogn. Instruct. 19, 479 (2001).

${ }^{7} \mathrm{~J}$. Minstrell, in Proceedings of the International Workshop: Research in Physics Learning-Theoretical Issues and Empirical Studies, edited by R. Duit, F. Goldberg, and H. Niedderer (The Institute for Science Education at the University of Kiel, IPN, 1992), pp. 110-128.

${ }^{8}$ A. Collins and W. Ferguson, Epistemic forms and epistemic games: Structures and strategies to guide inquiry, Educ. Psychol. 28, 25 (1993).

${ }^{9}$ D. Hammer, Student resources for learning introductory physics, Am. J. Phys. 68, S59 (2000).

${ }^{10}$ E. Redish, in Physics Education Research, Proceedings of the Varenna Summer School, "Enrico Fermi" Course CLVI, edited by E. Redish and M. Vicentini (Italian Physical Society, 2004), pp. 1-64.

${ }^{11}$ D. Hammer, A. Elby, R. Scherr, and E. F. Redish, Resources, framing, and transfer, in Transfer of Learning from a Modern Multidisciplinary Perspective, edited by J. Mestre (Information Age Publishing, 2005), pp. 89-119.

${ }^{12}$ M. Sabella and E. Redish, Knowledge organization and activation in physics problem solving, Am. J. Phys. (to be published).

${ }^{13}$ Note that we do not claim here that the structures we are developing somehow represent the "true" structure of the students" internal cognitive processes. At present, these are undetectable. Rather, what we offer is a way for observers of student behavior to organize and categorize their observations in what appears to be a sensible and productive fashion.

${ }^{14}$ J. Tuminaro, A Cognitive Framework for Analyzing and Describing Introductory Students' Use and Understanding of Mathematics in Physics, Ph.D. dissertation, University of Maryland, 2003, http://www.physics.umd.edu/perg/dissertations/Tuminaro/

${ }^{15}$ How People Learn: Brain, Mind, Experience, and School, edited by J. D. Bransford, A. L. Brown, and R. R. Cocking (National Academy Press, Washington, DC, 1999).

${ }^{16}$ L. C. McDermott and E. F. Redish, Resource Letter PER-1: Physics Education Research, Am. J. Phys. 67, 755 (1999).

${ }^{17}$ B. A. Thacker, Recent advances in classroom physics, Rep. Prog. Phys. 66, 1833 (2003).

${ }^{18} \mathrm{M}$. McCloskey, A. Caramazza, and B. Green, Curvilinear motion in the absence of external forces: Naïve beliefs about the motion of objects, Science 210, 1139 (1980).
${ }^{19}$ J. Clement, A conceptual model discussed by Galileo and used intuitively by physics students, in Mental Models, edited by D. Gentner and A. Stevens (Lawrence Erlbaum, 1983), pp. 325339.

${ }^{20} \mathrm{M}$. McCloskey, Naive theories of motion, in Mental Models (Ref. 20), pp. 289.

${ }^{21} \mathrm{C}$. Ioannides and S. Vosniadou, The changing meanings of force, Cognit. Sci. Q. 2, 5 (2002).

${ }^{22}$ A. Newell and H. Simon, Human Problem Solving (Prentice-Hall, Englewood Cliffs, NJ, 1972).

${ }^{23}$ A. Schoenfeld, Mathematical Problem Solving (Academic Press, New York, 1985).

${ }^{24} \mathrm{~W}$. Kintsch and J. Greeno, Understanding and Solving Word Arithmetic Problems, Psychol. Rev. 92, 109 (1985).

${ }^{25}$ A. Schoenfeld, Learning to think mathematically: problem solving, metacognition, and sense making in mathematics, in Handbook of Research in Mathematics Teaching and Learning, edited by D. Grouws (MacMillan, London, 1992), pp. 334-369.

${ }^{26} \mathrm{M}$. Chi, P. Feltovich, and R. Glaser, Categorization and representation of physics problems by experts and novices, Cogn. Sci. 5, 121 (1981).

${ }^{27} \mathrm{~J}$. Clement, Generation of spontaneous analogies by students solving science problems, in Thinking Across Cultures, edited by D. Topping, D. Crowell, and V. Kobayashi (Lawrence Erlbaum Associates, 1987), pp. 303-308.

${ }^{28} \mathrm{~J}$. Clement, Observed methods for generating analogies in scientific problem solving, Cogn. Sci. 12, 563 (1988).

${ }^{29}$ D. E. Trowbridge and L. C. McDermott, Investigation of student understanding of the concept of acceleration in one dimension, Am. J. Phys. 49, 242 (1981).

${ }^{30} \mathrm{~S}$. Rozier and L. Viennot, Students' reasoning in thermodynamics, Int. J. Sci. Educ. 13, 159 (1991).

${ }^{31} \mathrm{~J}$. Larkin, Understanding and teaching problem solving in physics, Eur. J. Sci. Educ. 1, 191 (1979).

${ }^{32}$ J. Larkin, J. McDermott, D. Simon, and H. Simon, Expert and novice performance in solving physics problems, Science $\mathbf{2 0 8}$, 1335 (1980).

${ }^{33}$ J. Larkin, Cognition of Learning Physics, Am. J. Phys. 49, 534 (1981).

${ }^{34}$ H. J. Kook and G. S. Novak, Jr., Representation of Models for Expert Problem Solving in Physics, IEEE Trans. Knowl. Data Eng. 3, 48 (1991).

${ }^{35} \mathrm{R}$. d'Andrade, The Development of Cognitive Anthropology (Cambridge University Press, Cambridge, England, 1995).

${ }^{36}$ G. Polya, How to Solve It (Princeton University Press, Princeton, NJ, 1945).

${ }^{37} \mathrm{P}$. Heller, R. Keith, and S. Anderson, Teaching problem solving through cooperative grouping. Part 1: Group versus individual problem solving, Am. J. Phys. 60, 627 (1992); P. Heller and M. Hollabaugh, Teaching problem solving through cooperative grouping. Part 2: Designing problems and structuring groups, ibid. 60, 637 (1992).

${ }^{38}$ The argument is sometimes made that "any software can be run on any computer" and therefore abstract arguments made about the nature of software apply to all computational systems. While this may be true in principle, in practice, hardware and time constraints strongly affect what kind of structures produce results efficiently and effectively (in time, for example, to escape a leaping tiger). For a phenomenological analysis of a real system, 
it is appropriate to take into account properties and constraints on the actual computing system-in this case, a human being.

${ }^{39}$ This term is used in the psychology literature as described here. See, for example, Ref. 49.

${ }^{40}$ J. R. Anderson, Cognitive Science and Its Implications, 6th Ed. (Worth, 2004).

${ }^{41}$ J. Fuster, Memory in the Cerebral Cortex: An Empirical Approach to Neural Networks in the Human and Nonhuman Primate (MIT Press, Cambridge, MA, 1999).

${ }^{42}$ J. Fuster, Cortex and Mind: Unifying Cognition (Oxford University Press, New York, 2003).

${ }^{43}$ R. Llinas, I of the Vortex: From Neurons to Self (MIT Press, Cambridge, MA, 2002).

${ }^{44}$ Fuster refers to such a network representing a basic element of knowledge as a cognit (short for cognitive bit). We will not use this term here as it does not appear to be in widespread use.

${ }^{45}$ The term "activate" here plays the role of the term more commonly used in physics education research, "elicit."

${ }^{46}$ E. Kandel, J. Schwartz, and T. Jessell, Principles of Neural Science, 4th Ed. (McGraw Hill, New York, 2000).

${ }^{47}$ D. O. Hebb, The Organization of Behavior (John Wiley \& Sons, New York, 1949).

${ }^{48}$ C. Kopec and R. Malinow, Matters of Size, Science 314, 1554 (2006).

${ }^{49}$ A. Baddeley, Human Memory: Theory and Practice, Revised Edition (Allyn and Bacon, Boston, 1998).

${ }^{50}$ J. Fuster, The Prefrontal Cortex: Anatomy, Physiology, and Neuropsychology of the Frontal Lobe, 3rd Ed. (Lippincott, Williams, and Wilkins, 1997).

${ }^{51}$ E. Goldberg, The Executive Brain: Frontal Lobes and the Civilized Mind (Oxford University Press, New York, 2002).

${ }^{52}$ The Prefrontal Cortex: Executive and Cognitive Functions, edited by A. C. Roberts, T. W. Robbins, and L. Weiskrantz (Oxford University Press, New York, 1998).

${ }^{53}$ The metaphor here is of computer code. Code that is written in a high level language, such as FORTRAN or C, must be interpreted into a form that the computer's processor can use. The translation of code into machine language is typically referred to as compilation and results in much faster processing than line-byline translation (viz., interpreted vs compiled code).

${ }^{54}$ A. Baddeley, Human Memory: Theory and Practice (Allyn and Bacon, Boston, 1998).

${ }^{55}$ E. F. Redish, R. E. Scherr, and J. Tuminaro, Reverse engineering the solution of a "simple" physics problem: Why learning physics is harder than it looks, Phys. Teach. 44, 293 (2006).

${ }^{56}$ A. Elby, Helping physics students learn how to learn, Am. J. Phys. 69, S54 (2001).

${ }^{57}$ J. Fuster, Cortex and Mind: Unifying Cognition (Ref. 42), p. 14.

${ }^{58}$ J. Schwarz and B. Sherin, in Keeping Learning Complex: Proceedings of the Fifth International Conference of the Learning Sciences (ICLS) (EuropIA, 2002), pp. 421-428.

${ }^{59}$ S. Loper and B. White, Talking Inquiry: 'Hypothetical Narratives' in Middle-School Students' Science Classroom Discourse, interactive poster presented at NARST Conference, Dallas, TX, Session 3B, Strand 2, April 5, 2005.

${ }^{60}$ Indeed, all reasoning in the end may depend on such phenomenologically developed intuitions. See, for example, G. Lakoff and M. Johnson, Metaphors We Live By (University of Chicago Press, Chicago, 1980); and L. Carroll, What the Tortoise Said to Achilles, Mind 4, 278 (1895).
${ }^{61}$ In cognitive neuroscience such phenomenological bound resources are referred to as "reflexive reasoning" (Ref. 42).

${ }^{62} \mathrm{~S}$. Dehaene, The Number Sense: How the Mind Creates Mathematics (Oxford University Press, New York, 1997).

${ }^{63}$ G. Lakoff and R. E. Núñez, Where Mathematics Comes From (Basic Books, New York, 2000).

${ }^{64}$ E. Berne, Games People Play: The Basic Handbook of Transactional Analysis (Ballentine Books, 1996).

${ }^{65} \mathrm{O}$. Morganstern and J. von Neuman, Theory of Games and Economic Behavior (Princeton University Press, Princeton, NJ, 1980).

${ }^{66}$ D. Hinsley and J. Hayes, From words to equations: Meaning and representation in algebra word problems, in Cognitive Processes in Comprehension, edited by $\mathrm{P}$. Carpenter and $\mathrm{M}$. Just (Lawrence Erlbaum, 1977), pp. 89-106.

${ }^{67} \mathrm{We}$ talk about these expectations and categorizations in terms of control structures we call epistemological framing. This process is discussed in Ref. 14.

${ }^{68}$ We may not have seen some common games as a result of the fact that our class de-emphasized the use of a textbook. None was required and few students bought the recommended one.

${ }^{69}$ We use the terms "conceptual" and "concepts" here loosely to mean any collection of interpretive ideas about a physical quantity or mechanism.

${ }^{70}$ In some sense, Pictorial Analysis is a collection of games rather than a single game. Each distinct kind of diagram-free-body diagram, circuit diagram, phase diagram, etc.- represents a distinct epistemic form and has its own distinct moves, conceptual resources, and end state. Refinement of this general game into more specific games will require further research.

${ }^{71}$ T. Ben-Zeev, When Erroneous Mathematical Thinking is Just as 'Correct': The Oxymoron of Rational Errors, in The Nature of Mathematical Thinking, edited by R. Sternberg and T. Ben-Zeev (Lawrence Erlbaum, 1996), pp. 55-79.

${ }^{72}$ T. Ben-Zeev, Rational Errors and the Mathematical Mind, General Review of Psychology 2, 366 (1998).

${ }^{73}$ American Heritage Dictionary (Houghton Mifflin, Boston, 2000).

${ }^{74}$ This relies on the measurement of aspects of the epistemological state using pre-post MPEX and measurement of aspects of the conceptual state using fractional gains on the FCI. Strong gains were obtained in both measures. These results will be documented elsewhere.

${ }^{75}$ D. Hestenes, M. Wells, and G. Swackhamer, Force Concept Inventory, Phys. Teach. 30, 141 (1992).

${ }^{76}$ R. K. Thornton and D. R. Sokoloff, Assessing student learning of Newton's laws: The Force and Motion Conceptual Evaluation, Am. J. Phys. 66, 338 (1998).

${ }^{77}$ E. F. Redish, J. M. Saul, and R. N. Steinberg, Student Expectations In Introductory Physics, Am. J. Phys. 66, 212 (1998).

${ }^{78}$ E. F. Redish, Teaching Physics with the Physics Suite (John Wiley \& Sons, Inc., New York, 2003).

${ }^{79}$ F. Marton and S. Booth, Learning and Awareness (Lawrence Erlbaum Associates, 1997), Chap. 6.

${ }^{80} \mathrm{~A}$ fourth student (a male) is present during this session but he contributes little and does not speak during the selected excerpts.

${ }^{81}$ This illustrates the fact that these students, having only recently learned Newton's laws and the use of forces, are not only solving the problem at hand in their discussion; they are taking steps in the process of compiling their Newtonian knowledge. See Ref. 55 for more discussion of this point. 
${ }^{82}$ At the time of the instructional intervention, Tuminaro was not consciously attempting to nudge "the students into playing a different epistemic game." It is only in the analysis, not in the actual event, that he used the concept of epistemic games to describe this episode.

${ }^{83}$ At an earlier point in the discussion, she accepts the idea that the temperature needed in the gas formula should be room temperature, even though it is not given. She says, "I'm assuming it's room temperature since it's not specified." This may not contradict our hypothesis since many classes in chemistry and physics take standard temperature and pressure as the assumed value when it is unspecified.

${ }^{84}$ E. Kim and S.-J. Pak, Students do not overcome conceptual difficulties after solving 1000 traditional problems, Am. J. Phys. 70, 759 (2002).

${ }^{85}$ This problem is adapted from D. P. Maloney, T. L. O'Kuma, C. J. Hieggelke, and A. Van Heuvelen, Surveying Students' Conceptual Knowledge of Electricity and Magnetism, Am. J. Phys. 69, S12 (2001). 